\title{
Experimental Study on Seismic Behavior of Precast Frame Columns with Vertical Reinforcement Spliced with Grouted Sleeve Lapping Connectors
}

\author{
Qiong Yu $\mathbb{D}^{\mathbb{D}},{ }^{1}$ Liang Zhang $\mathbb{D}^{1},{ }^{1}$ Shaohua Bai $\mathbb{D},{ }^{2}$ Baoxiu Fan $\mathbb{D}^{2},{ }^{2}$ Zhenhai Chen $\mathbb{D},{ }^{3}$ \\ and Ling-Zhi Li ${ }^{1}$ \\ ${ }^{1}$ Department of Disaster Mitigation for Structures, Tongji University, Shanghai 200092, China \\ ${ }^{2}$ Shanxi Construction Engineering Group Co., Ltd., Taiyuan 030013, Shanxi, China \\ ${ }^{3}$ Shanxi Erjian Group Co., Ltd., Taiyuan 030013, Shanxi, China
}

Correspondence should be addressed to Ling-Zhi Li; lilingzhi@tongji.edu.cn

Received 22 May 2021; Accepted 31 August 2021; Published 8 October 2021

Academic Editor: Young Hak Lee

Copyright (c) 2021 Qiong Yu et al. This is an open access article distributed under the Creative Commons Attribution License, which permits unrestricted use, distribution, and reproduction in any medium, provided the original work is properly cited.

Grouted splice connector is widely employed in precast concrete structures, but its utilization is still limited by shortcomings such as high construction cost, inconvenience in assemblage, and uncompacted grout caused by its small sleeve diameter. The grouted sleeve lapping connectors proposed by the authors can not only provide reasonable force transfer and convenient construction processing but also have the characteristics of low price and easy grouting. In this paper, the seismic performance of two full-scale precast concrete columns with two types of grouted sleeve lapping connectors was investigated, where type-I connector connected two lapped rebars and type-II connector connected four lapped rebars by a steel sleeve, respectively. A cast-in-situ column was also tested as a reference. All the specimens were tested under reversed cyclic horizontal load with a constant axial force. The distribution of cracks, failure modes, loading capacities, deformation abilities, stiffness, ductility, hysteresis loops, and energy dissipation of the specimens were studied. The type-I and type-II grouted sleeve lapping connectors satisfactorily transferred the stress of rebars when the columns reached their ultimate loads, and the seismic performance of the precast concrete columns was found to be comparable to that of the cast-in-situ column. Thus, the grouted sleeve lapping connector has a potential to replace the grouted splice connector in cast-in-situ connection.

\section{Introduction}

The reliable connection of rebars and the convenience of component assembly are the key factors to ensure construction quality in precast concrete structures. Grouted splice connector is a rebar connection widely employed in engineering practice. As shown in Figure 1(a), two rebars are placed head-to-head in a line crossing a sleeve, and then grout is injected into the gaps between the sleeve and the rebars to form one seamless whole. Since it was invented by Alfred in late 1960 for splicing reinforcement bars, the grouted splice connector has been extensively used and researched [1-7].

Test results provide valuable data on the effects of the sleeve diameter and the bar embedded length to the performance of the grouted splice connector, where decrease in sleeve diameter and increase in bar embedded length will improve the bond performance. Ling et al. [8] conducted an experimental study, where the sleeves were specially treated; four rebars with a diameter of $10 \mathrm{~mm}$ were welded to the inner surface of the sleeve to act as ribs, thus the bonding strength of the connector was improved. And, the precast columns using grouted sleeve couplers exhibited overall behavior, damage, and energy dissipation that were comparable to those of CIP column for up to a drift of 6\% [8]. Also, the experimental study conducted by Ling et al. [9] indicated that the failure modes of the grouted splice connector includes three types: (1) the rebar outside the sleeve being pulled off, (2) the slip between the rebar and the grout, (3) the grout in the sleeve being pulled off and pulled 


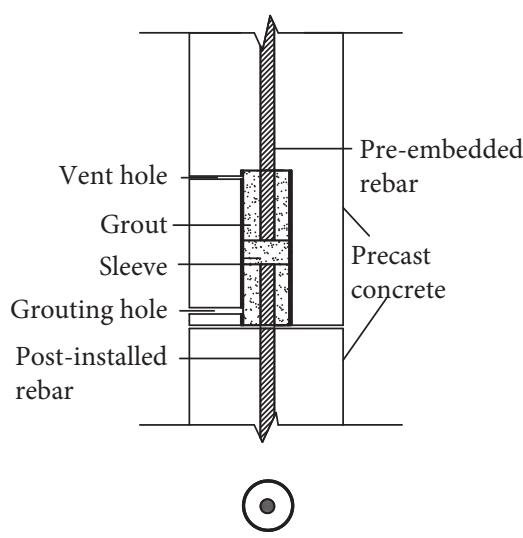

(a)

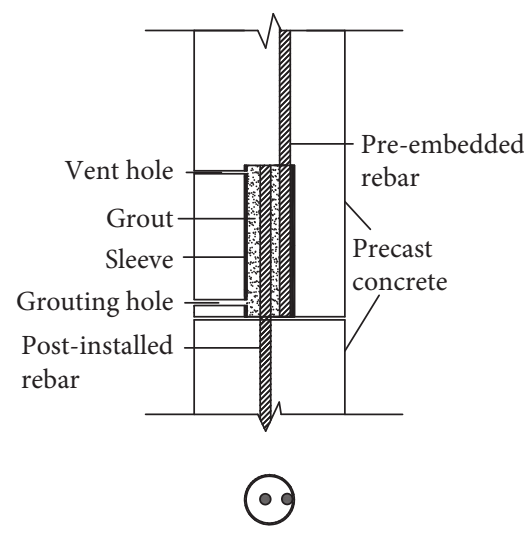

(b)

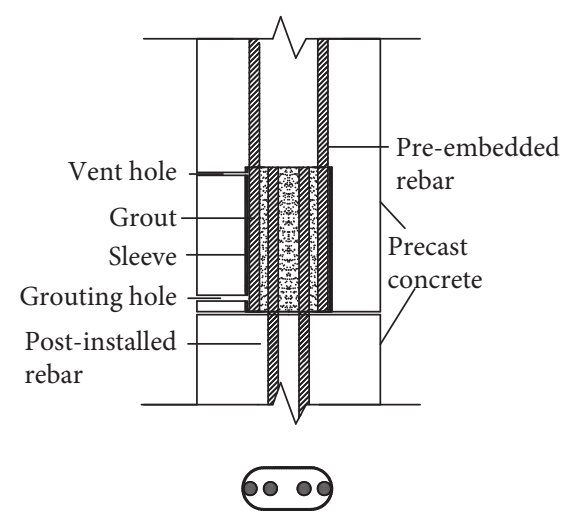

(c)

FIGURE 1: Forms of grouted connectors for reinforcement bars. (a) Grouted splice connector. (b) Type-I grouted sleeve lapping connector. (c) Type-II grouted sleeve lapping connector.

out when the sleeve's inner surface was not subjected to scoring treatment to increase bond strength. Einea et al. [10] found that a high splicing strength can be obtained by welding steel rings on the inside of the sleeve at both ends. However, if the inner surface of the grout-filled sleeve is not treated, the strength will not meet the requirements for connecting rebars.

A series of experimental studies have also been carried out on frame columns with grouted splice connectors. Riva [11] carried out quasi-static tests on five frame columns with different basic connections, which revealed that grouted sleeves ensured the precast columns a ductility similar to that of cast-in-situ column-foundation connections and pocket foundations, although a slightly lower dissipation capacity was observed. Column tests indicated that maximum tensile strain in the spliced bars close to the grouted couplers were 0.013 and 0.0034 under low and high axial loads, respectively, which were below the measured capacity of the splice. The precast columns with such splices and hooked transverse reinforcement showed comparable seismic performance with monolithic counterparts [12]. A cast-in-situ and six precast $1 / 3$-scale bridge column specimens were investigated by Wang et al. [13], and it was found that most precast columns have a $15 \%$ lower bearing capacity and energy-consuming capacity than cast-in-situ columns. The literature studies [14-16] showed that the bearing capacity and energy consumption capacity of precast columns and cast-in-situ column are basically the same.

As shown in Figure 1(a), the force transmission in a grouted splice connector is rebar-grout-sleeve-grout-rebar. In this force transmission path, the force is mainly transmitted through friction between the grouting material and the sleeve. The path is long and the force transmission is not direct enough. The sleeve not only constrains the grouting material in the circumferential direction but also resists tension in the axial direction. And, the opposite position of the two steel bars in the middle of the sleeve is the weakest position of the connector, which requires that the tensile bearing capacity of the sleeve should be at least greater than the tensile strength of the connected steel bars. In addition, in order to give a reliable constraint on the grouting material, the inner diameter of the grouted splice connector cannot be too large. In most cases, it is only $10 \mathrm{~mm}$ to $15 \mathrm{~mm}$ larger than the diameter of the rebar, which causes serious inconvenience to the assemblage of precast concrete members, especially when multiple rebars need to be connected in a precast connection. However, a reliable way to increase the grout-sleeve strength, i.e., embossing the inner surface of the sleeve is unfortunately costly. Furthermore, since the gap between the rebar and the sleeve is small, the quality of the connector cannot be guaranteed because the grout is hard to be made dense. The grouting strength is usually C80, and the maximum aggregate size must be less than $2.36 \mathrm{~mm}$, which also increases the cost.

In order to solve the aforementioned disadvantages of the grouted splice connector, the author proposed a grouted sleeve lapping connector with independent intellectual property rights in 2015 [17]. A type-I sleeve as shown in Figure 1(b) can be used to connect two overlapping rebars, and a single type-II sleeve as shown in Figure 1(c) can be used to connect four overlapping rebars to facilitate the assemblage when there are congested rebars in a precast concrete connector. The sleeve is derived from ordinary steel pipe, and the inner surface does not need to be treated. And, the grout (grouting strength is C60; due to the large diameter of the sleeve, the maximum particle size of the grouting aggregate can reach $4.75 \mathrm{~mm}$ ) in the sleeve performs as the force transmission media. The construction process of the grouted sleeve lapping connectors is as follows: (1) Prior to the casting of the two components of the precast concrete connection, the pre-embedded rebars are spot-welded to the inner surface of the sleeve to fix the position of the rebars initially instead of transferring the force, and both the sleeve with pre-embedded rebars and the post-installed rebars should be carefully positioned to facilitate the subsequent assemblage. (2) When concrete curing is completed, the two precast components are assembled and the post-installed rebars are inserted into the sleeves; grout is then injected into the gap between the rebars and the sleeve through the grouting hole. 
The authors have conducted comprehensive experimental studies on the performance of grouted sleeve lapping connectors with type-I sleeve [18-20]. In 2016, tensile tests were conducted on 16 specimens, in which the diameter of rebar was $18 \mathrm{~mm}$, and the lap lengths were $6 \mathrm{~d}, 8 \mathrm{~d}, 10 \mathrm{~d}, 12.5 \mathrm{~d}$ (where $\mathrm{d}$ is the diameter of the rebars). Another 63 specimens with an inner sleeve diameter of $70 \mathrm{~mm}$, a sleeve-wall thickness of $3 \mathrm{~mm}$, a rebar diameter of $12 \mathrm{~mm}-25 \mathrm{~mm}$, and an overlap length of $8 \mathrm{~d}, 10 \mathrm{~d}$, and $12.5 \mathrm{~d}$ were also tested $[18,19]$. In 2017, tensile tests on 36 specimens with an inner sleeve diameter of $79 \mathrm{~mm}$, a sleeve-wall thickness of $3.5 \mathrm{~mm}$, a rebar diameter of $20 \mathrm{~mm}-25 \mathrm{~mm}$, and a lap length of $6 \mathrm{~d}, 8$ $\mathrm{d}, 10 \mathrm{~d}$, and $12.5 \mathrm{~d}$ were tested, as well. These experiments show that there are two types of failure modes for the grouted sleeve lapping connector: (1) slip damage between rebar and grout, which occurs when sleeve length is not enough. (2) rebar pulling off from sleeve, which happens when the sleeve length is sufficient. However, grout pulling off from sleeve, which is frequently found in the grouted splice connector, was not found in the type-I grouted sleeve lapping connectors. In addition, due to the restraining effect of the sleeve, the bearing capacity of the connector was improved, thus reducing the overlap length of the connector. An overlap length of $12.5 \mathrm{~d}$ can be chosen for the type-I sleeve, which will ensure a yielding of rebar without connector damage.

The authors also carried out extensive tests on type-II grouted sleeve lapping connector. In 2016, 63 specimens were tested to investigate the influence of overlap length and rebar diameter on the performance of type-II connectors. According to the testing results, the overlap length of type-II sleeve with a diameter of less than $20 \mathrm{~mm}$ can be chosen as $20 \mathrm{~d}$, which will guarantee a yielding of rebar without connector damage $[18,19]$.

Compared to the grouted splice connector, the grouted sleeve lapping connector has a more reliable way of transmitting force, that is, rebar-grouting-rebar, which has a shorter force transmit path. The main role played by the sleeve is to constraint grout and the diameter of the connector can be much greater than that in the grouted splice connector, which facilitates construction, reduces cost significantly, and has the easier-to-compact grout.

Since the two steel bars in the sleeve are in opposite directions, the directions of their forces imposing on the sleeve (grouting) are also opposite. They cancel each other and form an interlocking phenomenon. In this way, the axial tension on the sleeve and the grout is small. And, there is no weak position of the sleeve. The preliminary tests $[18,19]$ proved that the tensile force of the sleeve is small; at the later stage of loading, the middle of the sleeve is axially compressed. Therefore, the sleeve has low material performance requirements and required no internal treatment; the grout has relatively low tensile performance requirements, which can be $\mathrm{C} 60$, and the maximum particle size of the grout can be controlled within $4.75 \mathrm{~mm}$, all of which make the connector cost relatively low. The performance comparison between the grouted sleeve lapping connector and the grouted splice connector is shown in Table 1.
Although the tensile performance of the grouted sleeve lapping connector has been proven much more satisfactory than that of the traditional grouted splice connector, its feasibility in real precast concrete members still needs to be verified. Therefore, a quasi-static test of two precast columns with this innovative connector will be conducted in this study, in which the longitudinal rebars are connected by type-I or type-II grouted sleeve lapping connectors. The seismic performance of the precast columns will be studied and compared with that of a reference cast-in-situ column. The strain of rebar and sleeve will also be investigated to analyze the working mechanism of the type-I and type-II sleeves.

\section{Experimental Program}

\subsection{Test Design}

2.1.1. Frame Column Design. The experimental tests investigated three full-scale frame columns, in which XZ1 is a cast-in-situ column, YZ1 and YZ2 are prefabricated columns with longitudinal bars connected by type-I and type-II grouted sleeve lapping connectors, respectively. All the columns tested have a $400 \mathrm{~mm} \times 400 \mathrm{~mm}$ cross section and a clear height of $1500 \mathrm{~mm}$. The concrete strength grades of the column and the base beam are C30 and C40 (according to the Chinese concrete design code [21]), respectively. The grade of rebar is HRB400, where HRB means high yield deformed rebars [21]. The stirrups in the column are composed of rebars with a diameter of $8 \mathrm{~mm}$ and a spacing of $100 \mathrm{~mm}$. The longitudinal reinforcement of the column is twelve rebars with a diameter of $16 \mathrm{~mm}$. The geometry and reinforcement of the tested columns are shown in Table 2 and Figure 2.

As is shown in Figures 2(a) and 2(d), the specimen $\mathrm{XZ1}$ is a typical cast-in-situ column-to-foundation connection. As is shown in Figures 2(b) and 2(e), YZ1 is a prefabricated column-to-foundation connection, where twelve type-I sleeves with an inner diameter of $60 \mathrm{~mm}$ and a thickness of $3 \mathrm{~mm}$ are pre-embedded in the column. The longitudinal rebars of the column (termed as the upper rebars as shown in Figure 2(b)) are spot-welded to the inner surface of the sleeves. Twelve rebars with a diameter of $16 \mathrm{~mm}$ are pre-embedded in the base beam (termed as the lower rebars as shown in Figure 2(b)), whose positions are corresponding to the sleeves in the prefabricated column. Each grouted sleeve connects the upper rebar in the column and the lower rebar in the base beam over a lapping length of $200 \mathrm{~mm}$, by transferring stress entirely from one bar to the other through the grout in the sleeve. The reinforcement of YZ2 is shown in Figures 2(c) and 2(f), where four type-I and another four type-II sleeves are embedded in the corners and near the mid-sides of the column section, respectively. The construction procedure of the type-I sleeves is the same as those in YZ1. For each type-II sleeve, the two upper bars along each column side are spot-welded to the inner surface of the sleeve, then the corresponding two lower rebars in the base beam are connected to them by the type-II grouted sleeve. The 
TABLE 1: Comparison of two connectors.

\begin{tabular}{|c|c|c|c|c|c|c|}
\hline Object & Casting process & Connector length $(\mathrm{d})$ & $\begin{array}{c}\text { Fault } \\
\text { tolerance }\end{array}$ & Grouting defect & Construction schedule & Cost \\
\hline Grouted splice connector & Complex & 16 & Low & Not dense & Normal speed & High \\
\hline Grouted sleeve lapping connector & Simple & 12.5 & High & Dense & Fast & Low \\
\hline
\end{tabular}

TABLE 2: Casting method of the specimen and connection form of the longitudinal steel bar.

\begin{tabular}{lccc}
\hline Specimen & Concrete casting & Form of sleeve & Corner connector \\
\hline XZ1 & Cast-in-place & - & - \\
YZ1 & Prefabricated & Type-I $(\phi 60$, length $200 \mathrm{~mm})$ & Type-I $(\phi 60$, length $200 \mathrm{~mm})$ \\
YZ2 & Prefabricated & Type-II (width $60 \mathrm{~mm}$, length $130 \mathrm{~mm}$, height $320 \mathrm{~mm})$ & Type-I $(\phi 60$, length $200 \mathrm{~mm})$ \\
\hline
\end{tabular}

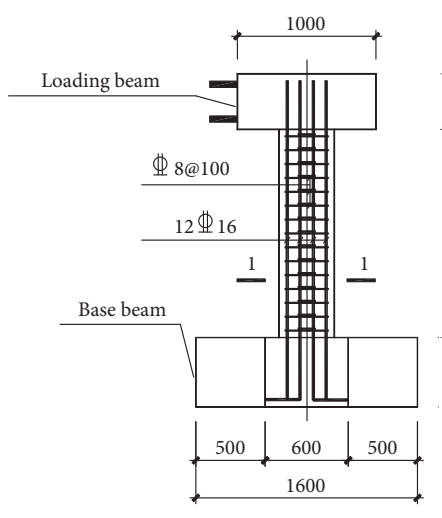

(a)

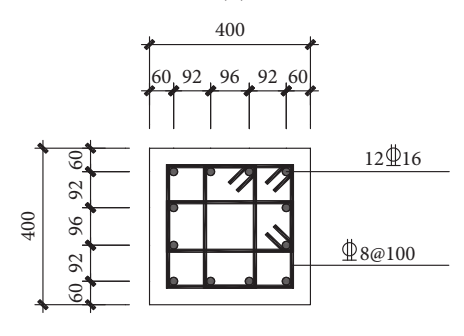

(d)

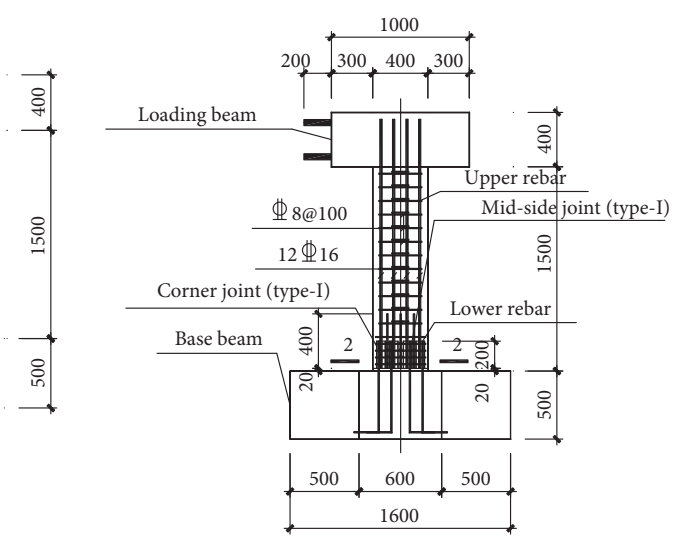

(b)

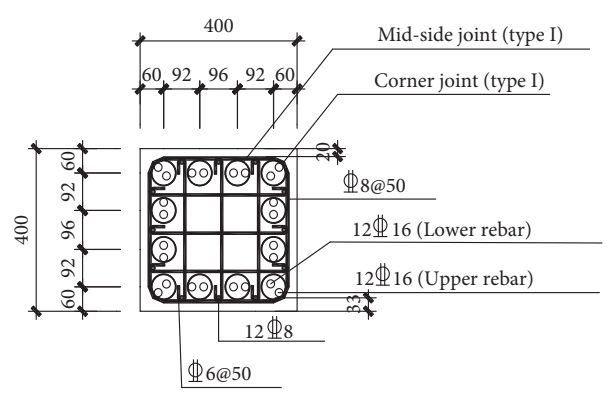

(e)

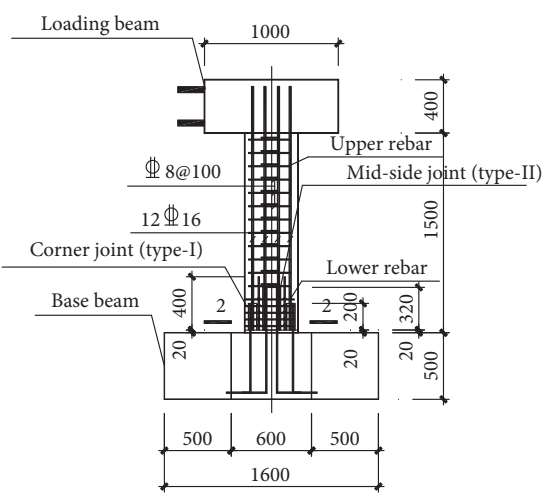

(c)

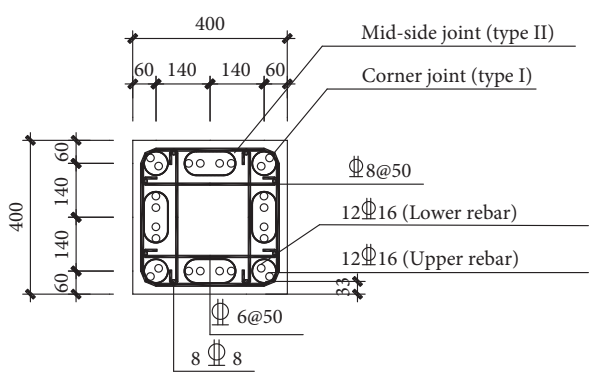

(f)

Figure 2: Details of column-base joints. (a) Front elevation of XZ1. (b) Front elevation of YZ1. (c) Front elevation of YZ2. (d) Section 1-1 of XZ1. (e) Section 2-2 of YZ1. (f) Section 2-2 of YZ2.

length of the sleeves and the lapping length of the rebars are both $320 \mathrm{~mm}$.

The thickness of the concrete cover is $25 \mathrm{~mm}$. In order to improve the deformation ability of the concrete outside the sleeves and avoid premature detachment, the spacing of stirrups within the range of $320 \mathrm{~mm}$ from the top surface of the base beam is changed to $50 \mathrm{~mm}$; anther twelve vertical rebars with a diameter of $8 \mathrm{~mm}$ and a length of $400 \mathrm{~mm}$, together with eight layers of additional links with a diameter of $6 \mathrm{~mm}$ and a spacing of $50 \mathrm{~mm}$ are employed within this range. The space between the columns YZ1, YZ2, and the base beam is $20 \mathrm{~mm}$.
2.1.2. Sleeve Design. The dimensions of the type-I and typeII sleeves for the test are shown in Figure 3. A cover plate is added to the top of the sleeve to prevent concrete from entering the inside of the sleeve when the specimen is casted. Holes are drilled at the edge of the cover plate, whose diameters are $2 \mathrm{~mm}$ larger than the diameter of the upper rebars to facilitate the installation. A vent hole and a grouting hole are formed in the side wall of the sleeve to facilitate the grout injection. Their inner diameters are $14 \mathrm{~mm}$ and $27 \mathrm{~mm}$, respectively, and the nearest edges of the vent and grouting holes are $20 \mathrm{~mm}$ from the upper and lower ends of the sleeve. 


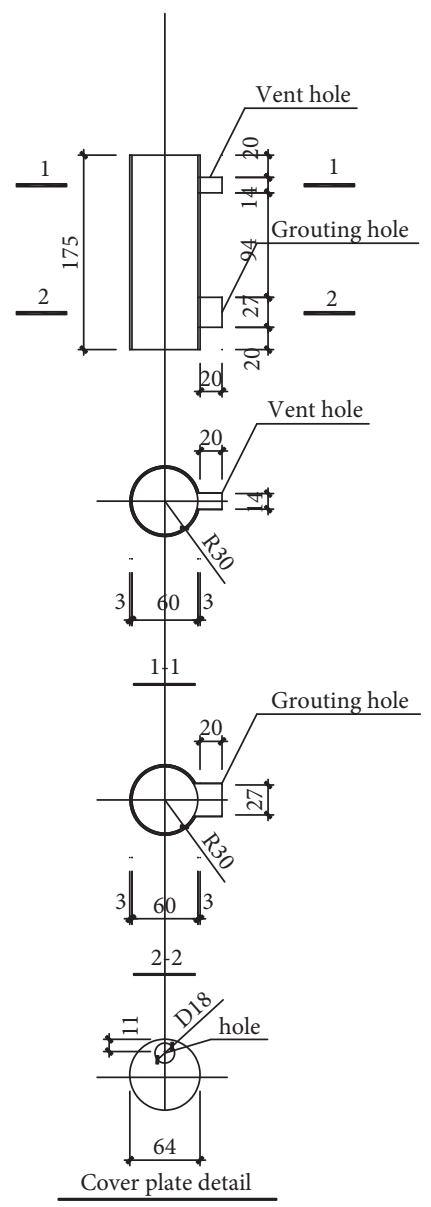

(a)

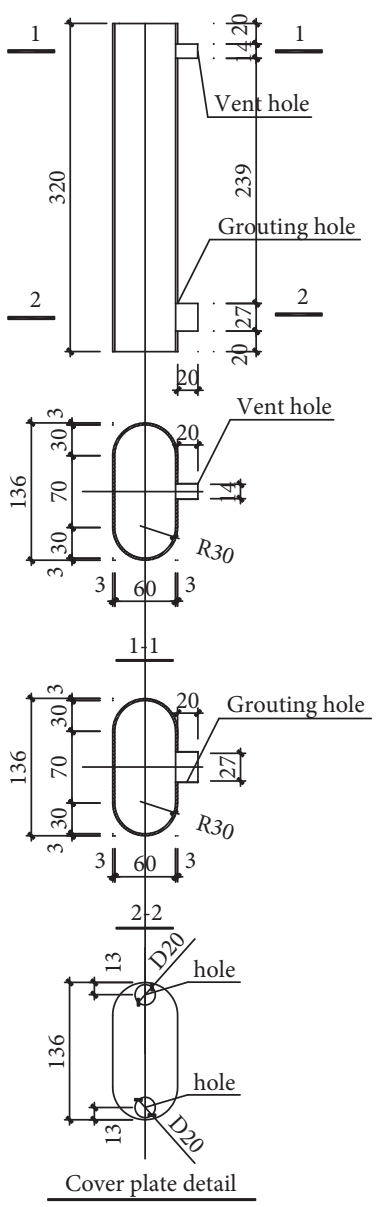

(b)
Figure 3: Details of sleeves. (a) Type-I sleeve. (b) Type-II sleeve.

2.1.3. Assemblage and Grouting of Frame Columns. The assemblage and grouting process of the specimens are shown in Figure 4. Before the base beam and the column are hoisted for assemblage, the joint surfaces are manually chiseled to expose coarse aggregates. A $20 \mathrm{~mm}$ thick steel spacer is placed on the joint surface to reserve a gap, and the periphery of the gap is blocked using epoxy resin, thus a cavity of $20 \mathrm{~mm}$ thickness is formed to facilitate the grout injection. Then, pressure grouting is used to inject grout from the grouting hole in one of the sleeves, the rest of the grouting holes are blocked, thus the grout will flow into other sleeves through the gap. When grout overflows from all the vent holes, the grouting is completed.

2.2. Test Materials. The strength grade of reinforcing steel is HRB400, and the basic mechanical properties are obtained by tensile test as shown in Table 3 .

H40-type grouting material is used in this experimental study, the 28-day compressive strength is no less than $60 \mathrm{MPa}$, and the properties are shown in Table 4. Six $40 \mathrm{~mm} \times 40 \mathrm{~mm} \times 160 \mathrm{~mm}$ flexural specimens and three $150 \mathrm{~mm} \times 150 \mathrm{~mm} \times 150 \mathrm{~mm}$ split tensile specimens are fabricated. The mean values of flexural and compressive strength are $10.77 \mathrm{MPa}$ and $77.98 \mathrm{MPa}$, and the mean value of splitting tensile strength is $4.33 \mathrm{MPa}$. The compressive strength of concrete cubes of the column and the base beam are $30.9 \mathrm{MPa}$ and $42.4 \mathrm{MPa}$, respectively.

The sleeves are made of Q235B seamless steel tube. Dog bone specimens are made for unidirectional tensile test. The tested yield strength is $266.99 \mathrm{MPa}$, the tensile strength is 417.16 $\mathrm{MPa}$, and the elastic modulus is $184 \mathrm{GPa}$.

\subsection{Experimental Setup}

2.3.1. Loading Device. The quasi-static test of the frame columns is carried out in the Structural Static Test Laboratory of Tongii University. The experimental setup is shown in Figure 5, in which the base beam was anchored to the firm ground, and a compressive load was imposed on the top of the column by three hydraulic jacks, where the axial compression ratio is 0.24 , which was determined as

$$
n=\frac{N}{f_{c} b h}
$$

where $n$ is the axial compression ratio, $f_{c}$ is the measured value of concrete compressive strength, and $b$ and $h$ are the sectional breadth and height of the column, respectively. For all the tests, the axial force $N$ was set to be $800 \mathrm{kN}$.

A horizontal low cyclic loading was imposed on the top end of the column, of which the loading history follows a force-displacement hybrid control. According to the code concrete specifications [21], the theoretical yield load for the column specimens was computed as $114 \mathrm{kN}$. Therefore, the first two steps of the horizontal loading should be controlled by force, and the magnitudes were set to $50 \mathrm{kN}$ and $100 \mathrm{kN}$ (up to the column yield load). In each step, a cycle of one push (defined as positive direction) and one pull (defined as negative direction) were imposed on the specimens.

Then, the displacement control method was adopted, and the step increment was chosen as $4 \mathrm{~mm}$. The horizontal displacement was cycled once in the first loading step (where the displacement is $\Delta=4 \mathrm{~mm}$ ), and it was cycled twice in each loading step during the subsequent loading process. When the bearing capacity of the specimen dropped to $85 \%$ of the peak load $\left(F_{\mathrm{p}}\right)$ for the first time, its loading process was terminated and the specimen reached the failure state.

The loading history of the horizontal load is shown in Figure 6.

2.3.2. Arrangement of Instrumentation. The arrangement of strain gauges is shown in Figure 7. In order to calibrate the strain variation of the steel reinforcement, strain gauges were attached onto eight steel rebars for both YZ1 and YZ2. Two positions were calibrated for each rebar, one was $20 \mathrm{~mm}$ above the top surface of the base beam, and the other was $20 \mathrm{~mm}$ above the top end of sleeve, as shown in Figures 7(a)$7(\mathrm{c})$.

The transverse strain of the sleeves is measured as shown in Figures 7(d) and 7(e), the strain gauges named by odd numbers is relatively close to the lower rebars inside the sleeve, and that named by even numbers are relatively far away from the lower rebars. 


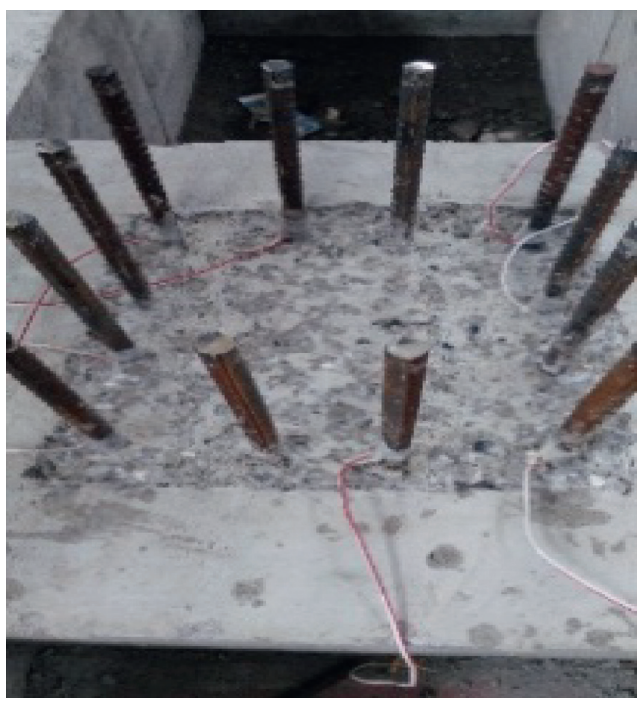

(a)

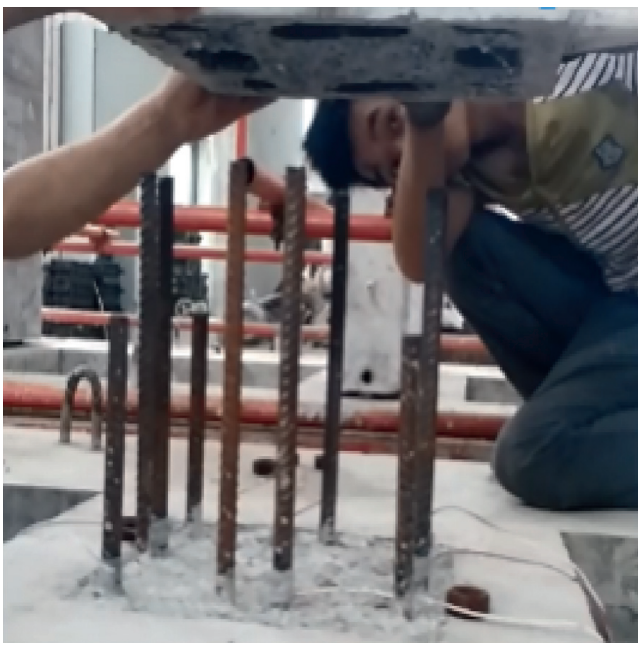

(c)

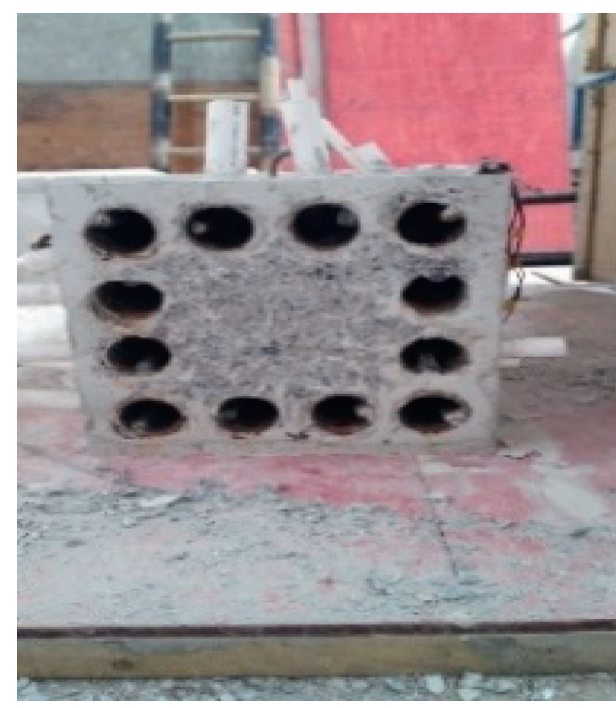

(b)

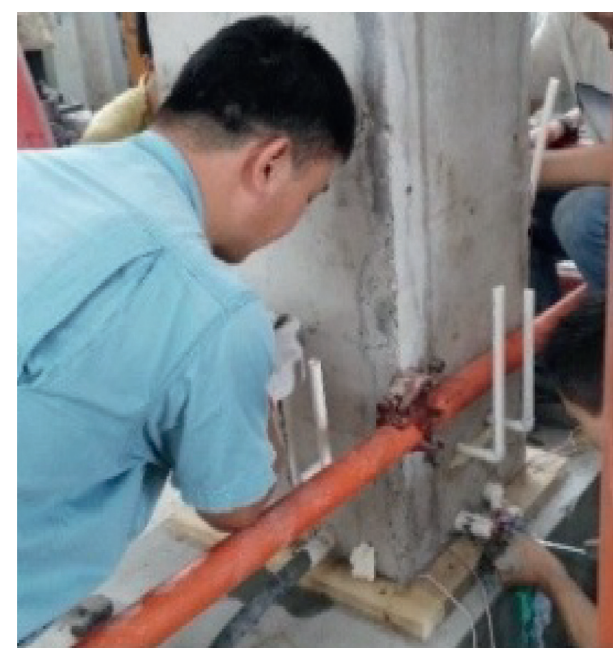

(d)

Figure 4: Assemblage and grouting of a column-base joint. (a) Chiseled joint surface on the base beam. (b) Chiseled joint surface on the column. (c) Assemblage of column onto the base beam. (d) Pressure grouting.

TABLE 3: Mechanical parameters of the reinforcing bar.

\begin{tabular}{lcc}
\hline Diameter $(\mathrm{mm})$ & Average yield strength $(\mathrm{MPa})$ & Average ultimate strength $(\mathrm{MPa})$ \\
\hline 6 (tension bars in prefabricated columns) & 542.36 & 661.13 \\
8 (snap) & 465.40 & 658.85 \\
16 (longitudinal reinforcement) & 499.88 & 655.62 \\
\hline
\end{tabular}

TABLE 4: Grouting material performance parameters.

\begin{tabular}{lcr}
\hline Grouting performance & & Measurements value \\
\hline & Initial value & 297 \\
Fluidity $(\mathrm{mm})$ & After 30 minutes & 288 \\
& After 3 hours & 0.22 \\
Vertical expansion rate $(\%)$ & The difference between 24 hours and 3 hours of expansion & 0.15 \\
Maximum aggregate size $(\mathrm{mm})$ & & $\leq 4.75$ \\
\hline
\end{tabular}

The arrangement of linear variable differential transformers (LVDTs) is shown in Figure 8. Eight LVDTs are employed for each specimen, and the arrangement of LVDTs is the same for all the specimens. The LVDT on the base beam (named as DM-8) is used to measure the overall horizontal movement that may exist during the loading 

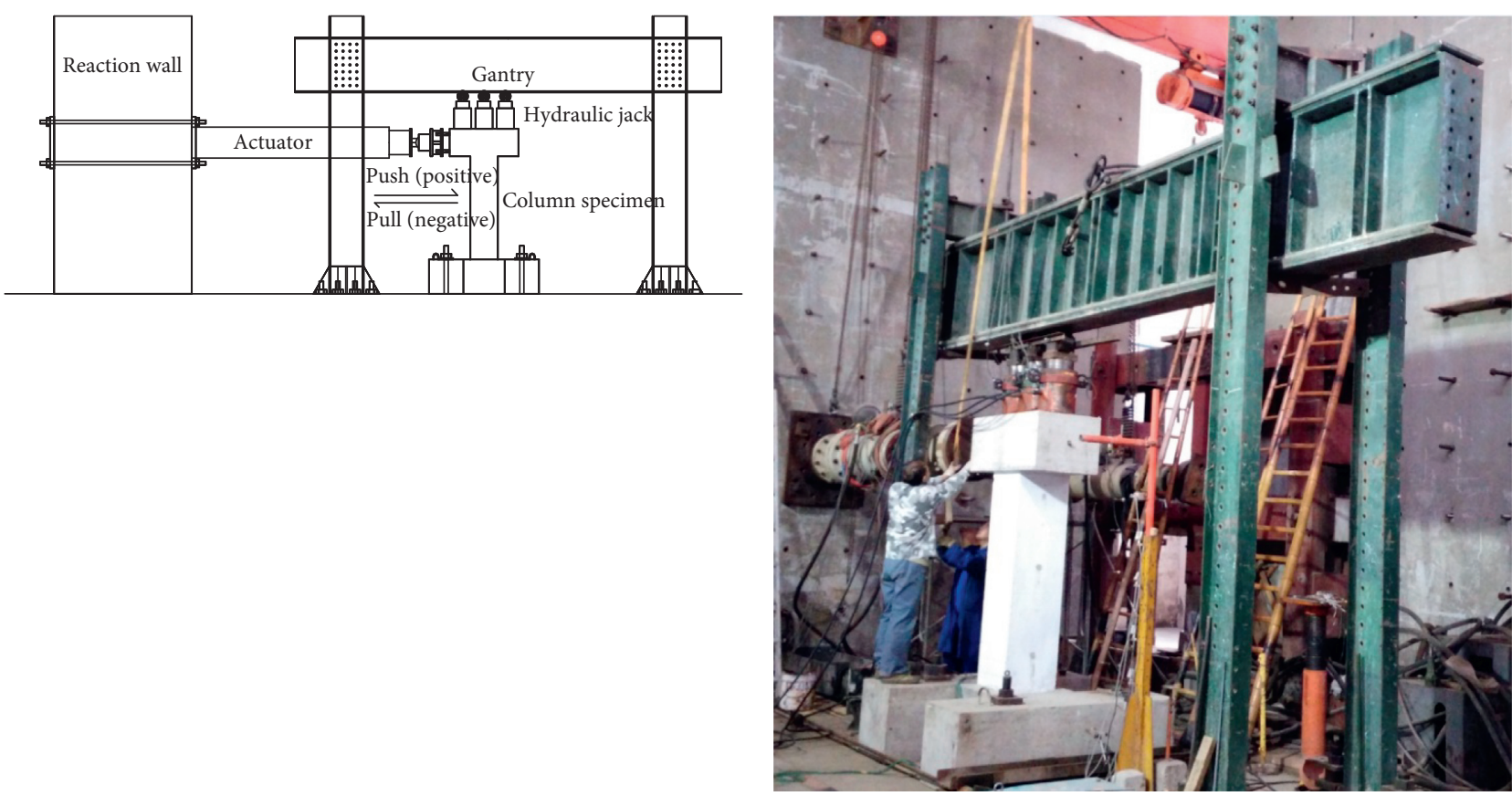

(a)

(b)

Figure 5: Loading device and specimen setup. (a) Schematic diagram. (b) Picture.

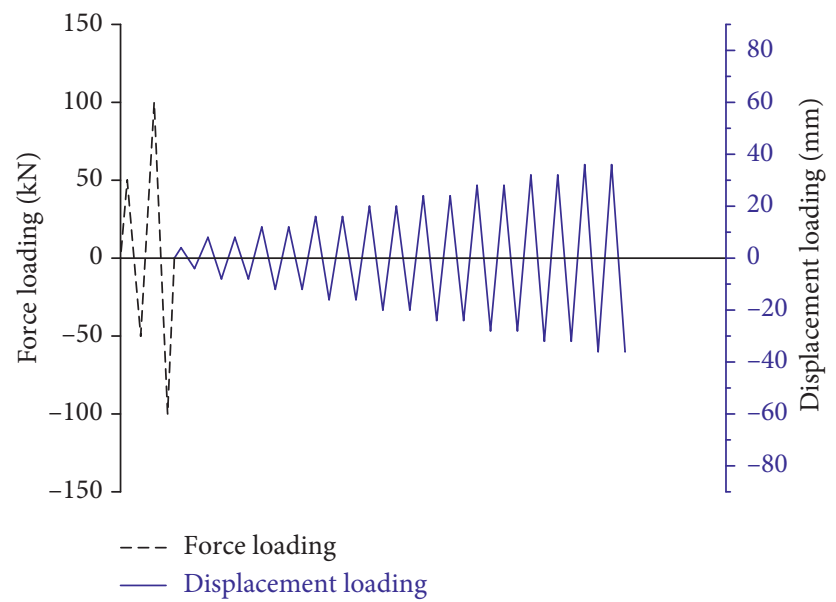

FIGURE 6: Loading history.

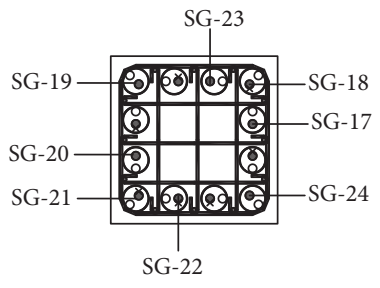

(a)

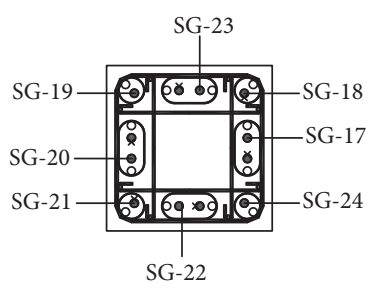

(b)

FIgURE 7: Continued. 


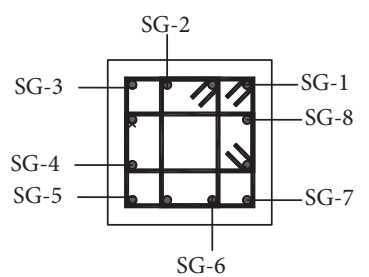

(c)

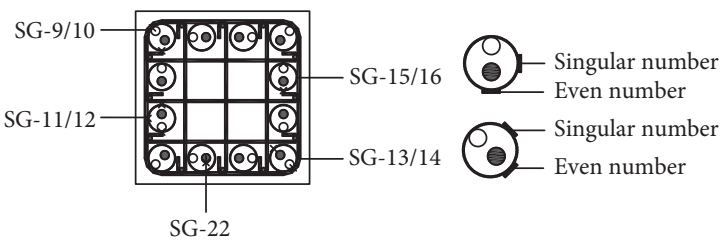

(e)

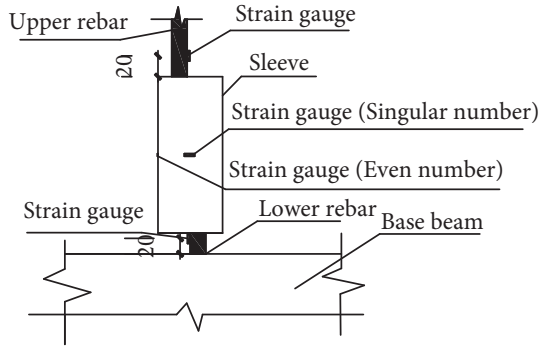

(d)
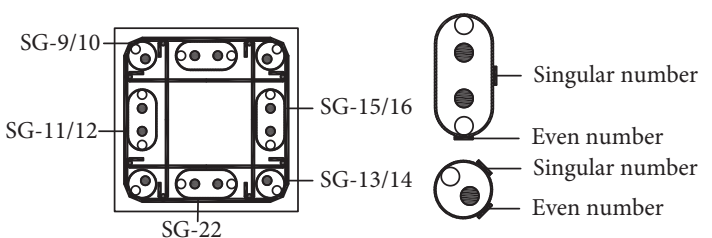

(f)

Figure 7: Arrangement of strain gauge for YZ1 and YZ2. (a) On rebars of YZ1, $20 \mathrm{~mm}$ above the base beam. (b) On rebars of YZ2, $20 \mathrm{~mm}$. (c) On rebars of YZ1 and YZ2, $20 \mathrm{~mm}$ above the top end of sleeve above the base beam. (d) Sleeve strain gauges. (e) On sleeves of YZ1, at the mid-height of sleeves. (f) On sleeves of YZ2, at the mid-height of sleeves.

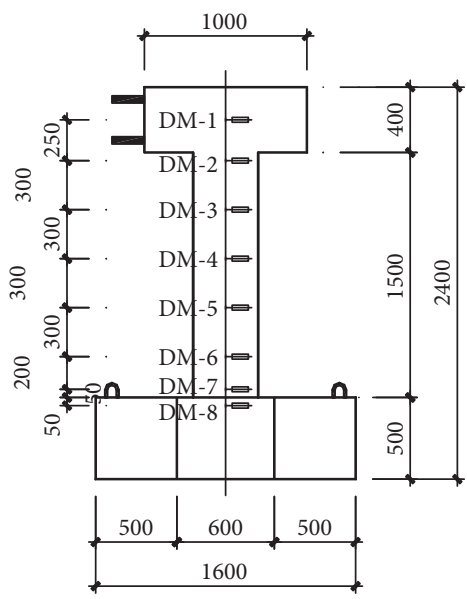

(a)

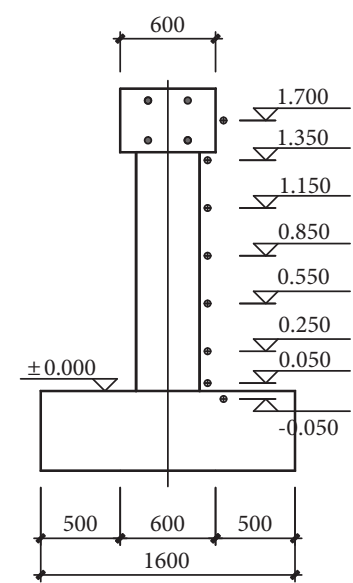

(b)

Figure 8: Arrangement of LVDTs. (a) Rear view. (b) Left view.

process of the column. The LVDT (DM-1) at the level of the horizontal hydraulic jack is used to calibrate the horizontal displacement of the top of the column, while the rest of the LVDTs (DM-2 DM-7) on the column is used to reflect the deformation of the column during the loading process.

\section{Results and Discussion}

3.1. Failure Modes and Crack Pattern. Two horizontal cracks formed on the left and right sides of Column XZ1 at a level of $100 \mathrm{~mm}$ higher than the top surface of the base beam when the horizontal force $(F)$ reached $100 \mathrm{kN}$. A horizontal and a vertical crack appeared on the left side of the column, and two horizontal cracks appeared on the right side, when the horizontal displacement $(\Delta)$ was $16 \mathrm{~mm}$. As the original crack continued to develop, a crack on the left side began to develop obliquely to the lower right. When $\Delta=24 \mathrm{~mm}$, the oblique cracks caused by positive and negative horizontal loads continued to develop, thus intersected in the middle of the column. And, vertical cracks also appeared on the right side of the column. The crack on the left side of the column reached the maximum value of $2 \mathrm{~mm}$ at a displacement level of $\Delta=44 \mathrm{~mm}$. The concrete in the lower left corner of the column crushed and peeled off as the displacement reached $\Delta=48 \mathrm{~mm}$, and the crack no longer developed obviously thereafter. At last, XZ1 reached the displacement limit state when the horizontal displacement reached the ultimate displacement $\Delta u=66 \mathrm{~mm}$.

The first horizontal crack of YZ1 occurred on the concrete cover near the top end of the right sleeve, which was 
$220 \mathrm{~mm}$ above the top surface of the base beam, when the horizontal displacement reached $4 \mathrm{~mm}$. When the displacement reached $12 \mathrm{~mm}$, the horizontal cracks on the left and right sides intersected in the middle of the column. As the displacement approached $\Delta=16 \mathrm{~mm}$, a horizontal crack appeared on the left side of the column, and the original crack began to propagate obliquely. Gradually, vertical cracks appeared on the left side, and horizontal cracks formed between the column and the grouting layer at a load level of $\Delta=24 \mathrm{~mm}$. As the horizontal displacement approaching $\Delta=32 \mathrm{~mm}$, vertical cracks gradually formed on the lower right corner of the column, and the horizontal cracks between the column and the grouting layer continued to develop, up to the maximum crack width of $2 \mathrm{~mm}$. When $\Delta=56 \mathrm{~mm}$, the concrete in the lower left corner of the column began to crush, then the surface concrete spalled off. After that, the cracks on the column stopped developing and YZ1 reached the displacement limit state as the horizontal displacement reached $\Delta u=72 \mathrm{~mm}$.

Horizontal cracks appeared on the left and right sides of YZ2, which were about $220 \mathrm{~mm}$ above the base beam, as the horizontal displacement reached $8 \mathrm{~mm}$. Up to a horizontal displacement of $12 \mathrm{~mm}$, cracks appeared in the joint between the column and the grout layer. When $\Delta=16 \mathrm{~mm}$, the original cracks almost intersected in the middle of the column, and vertical cracks appeared. When $\Delta=24 \mathrm{~mm}$, the greatest crack width between the right column and the grouting layer was about $1 \mathrm{~mm}$. The concrete in the lower left corner began to fall off, where the vertical crack was about $45 \mathrm{~mm}$ in length as the displacement reached $46 \mathrm{~mm}$. When $\Delta=56 \mathrm{~mm}$, the corner concrete spalled off and the crack no longer developed significantly. Finally, YZ2 reached the displacement limit state as the horizontal displacement reached $\Delta u=70 \mathrm{~mm}$.

Figure 9 shows the damage to the left and right of the bottom of the column in the displacement limit state. It is obvious that the damage was mainly the crushing and falling of the concrete at the corner of the column. In comparison, the precast column corner sleeve had a certain restraint on the concrete, so the crushed section at the corner of the precast column was shorter than the cast-in-situ column. However, due to the existence of the sleeve, the crack resistance of the outer concrete cover was weaker than that of the overall concrete, so the vertical cracks on both sides of the column along the edge of the sleeve extended upwards than the cast-in-situ column.

Figure 10 shows the crack distribution of the three columns in the displacement limit state. In general, the failure modes of the precast columns were basically the same as that of the cast-in-situ column. The difference was that the first horizontal crack of the cast-in-situ column appeared at a level of $100 \mathrm{~mm}$ above the base beam, while that of the precast columns appeared at $220 \mathrm{~mm}$ above the base beam, i.e., above the top end of the sleeves. And, the occurrence of the cracks in the precast columns was later than the cast-insitu column. The main reason for the above phenomena was that the sleeves provided considerable restraining, thus reducing the longitudinal strain of concrete and preventing the concrete from cracking horizontally. Secondly, the crack development of YZ1 and YZ2 was also different from each other. Although horizontal cracks occurred near the top end of the type-I sleeves, the horizontal crack in YZ2 did not penetrate horizontally but developed obliquely downward, because the type-II sleeves in YZ2 were much longer than the type-I sleeves; thus, the horizontal development of cracks was suppressed.

Because additional stirrups and vertical rebars are provided outside the sleeves in the joint region, the concrete cover outside the sleeves did not fall off in this test, as shown in Figure 11. No slippage between the concrete/grout and the reinforcing steel/sleeves was found.

\subsection{Hysteresis Curve and Energy Dissipation Capacity.} The horizontal force-displacement hysteresis curves of the specimens and the corresponding skeleton curves are shown in Figures 12 and 13, respectively.

Compared with the cast-in-situ column, the precast columns had plumper hysteresis curves, thus had better energy consumption capacity and higher bearing capacity. The three skeleton curves almost overlapped under small displacement, but the skeleton curve of the cast-in-situ column had obvious peaks, while the precast columns did not. That is, when the displacement exceeded the displacement corresponding to the peak load $(\Delta>\Delta p)$, the bearing capacity of the cast-in-situ column decreased abruptly with a sudden degradation, while that of the precast columns decreased gradually.

According to the Chinese code, "Specification of Test Methods for Earthquake Resistant Building" (JGJ/T 1012015) [22], the energy dissipation capacity of a column is usually measured by the energy consumption coefficient $E$ and the equivalent viscous damping coefficient $D$ as

$$
\begin{aligned}
& E=\frac{S_{A B C}+S_{C D A}}{S_{O B A}+S_{O D F}}, \\
& D=\frac{1}{2 \pi} \cdot \frac{S_{A B C}+S_{C D A}}{S_{O B E}+S_{O D F}},
\end{aligned}
$$

where SABC, SCDA, SOBE, and SODF are the areas underneath the curve in Figure 14.

Figures 15 and 16 show the relationship between the energy dissipation coefficient, the equivalent viscous damping coefficient, and the horizontal displacements of the specimens. It can be seen that under the same displacement conditions, the energy consumption curve of the precast column was consistent with the cast-in-situ column before $\Delta=44 \mathrm{~mm}$, and the energy consumption capacity of YZ1 was slightly higher than the other two test pieces after that point. Under the same displacement conditions, the viscous damping coefficients of all the columns were basically the same before $\Delta=28 \mathrm{~mm}$, and hence forward, the viscous damping coefficient of the cast-in-situ column was larger than that of the precast columns, and the gap increased gradually as the displacement increased.

Table 5 shows the energy dissipation coefficient $(E)$ and the equivalent viscous damping coefficient $(D)$ of the specimens under the displacement limit state. The energy 


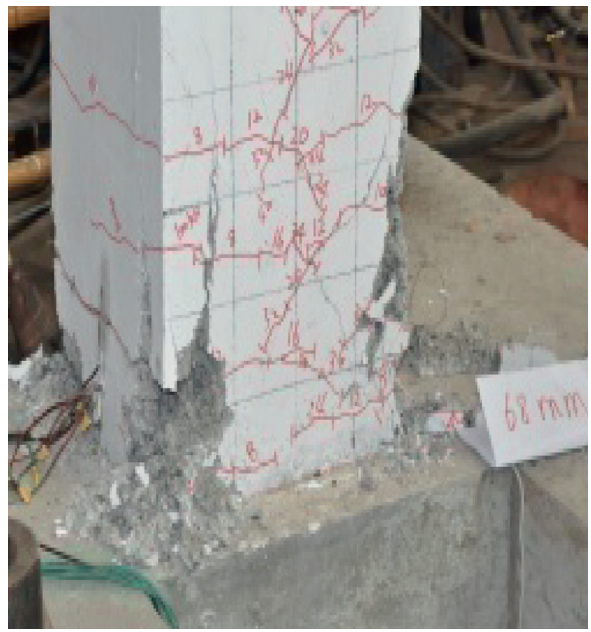

(a)

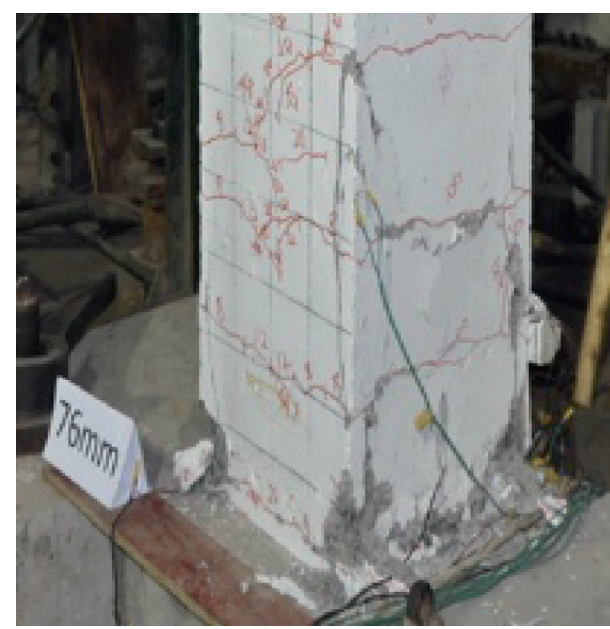

(c)

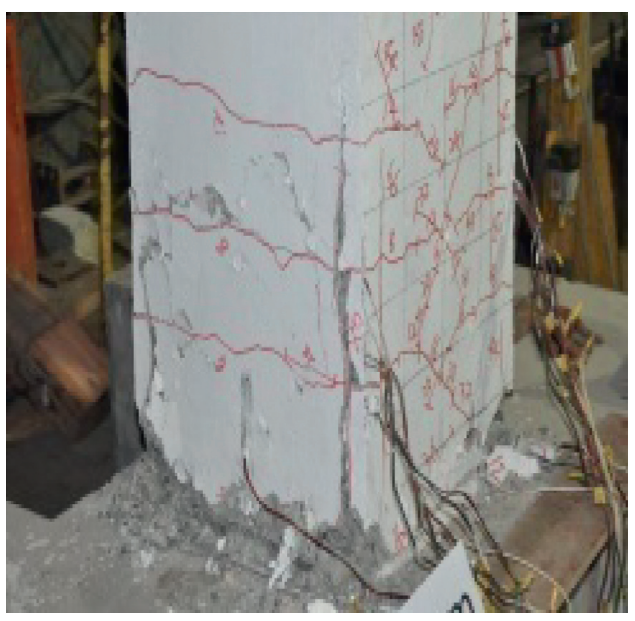

(e)

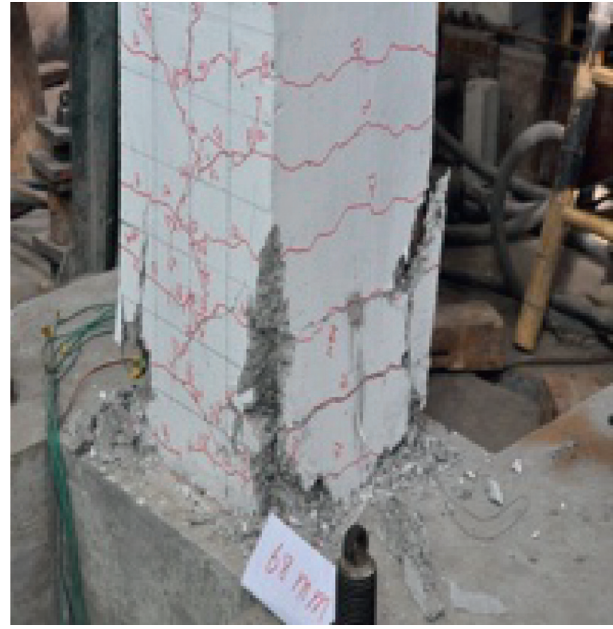

(b)

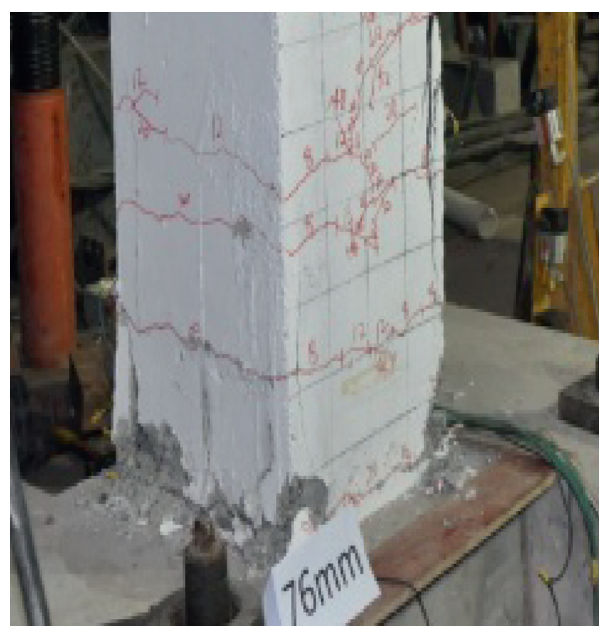

(d)

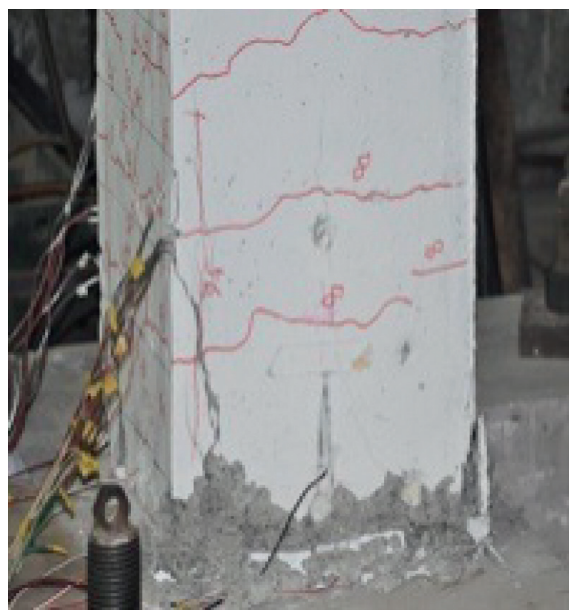

(f)

Figure 9: Crack patterns of specimens at displacement limit state. (a) Left side of XZ1. (b) Right side of XZ1. (c) Right side of YZ1. (d) Left side of YZ1. (e) Left side of YZ2. (f) Right side of YZ2.

dissipation capacity of the precast columns was about 1.2 times that of the cast-in-situ column, and its equivalent viscous damping coefficient was approximately equal to the cast-in-situ column.
3.3. Bearing Capacity. When the first crack was observed in the tension zone of the column, the corresponding horizontal load was defined as the cracking force $\left(F_{\mathrm{cr}}\right)$. When the outermost reinforcement layer of the column was subjected 


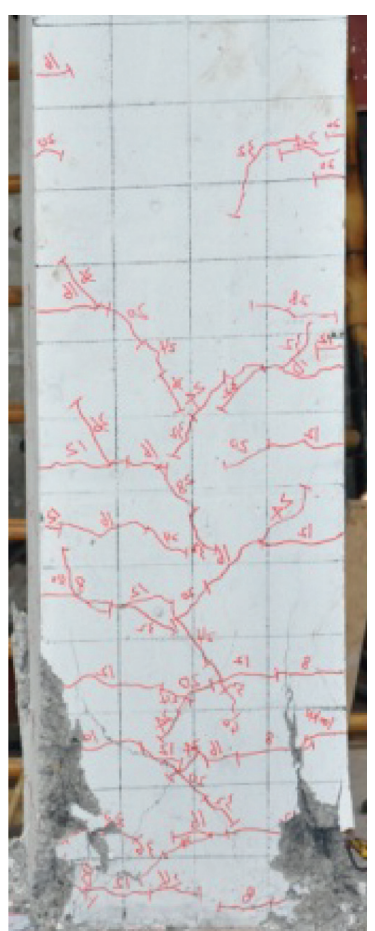

(a)

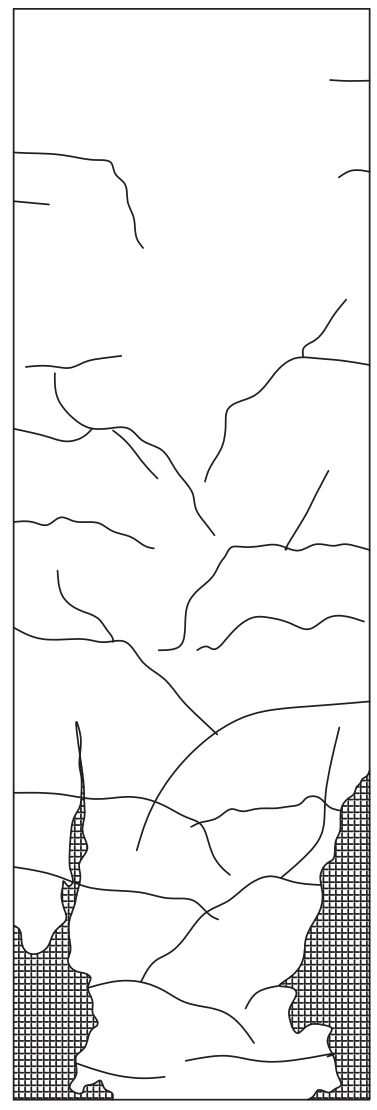

(d)

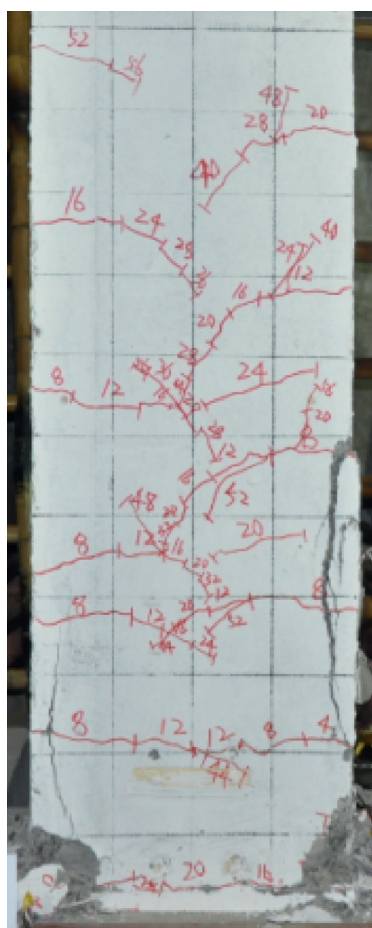

(b)

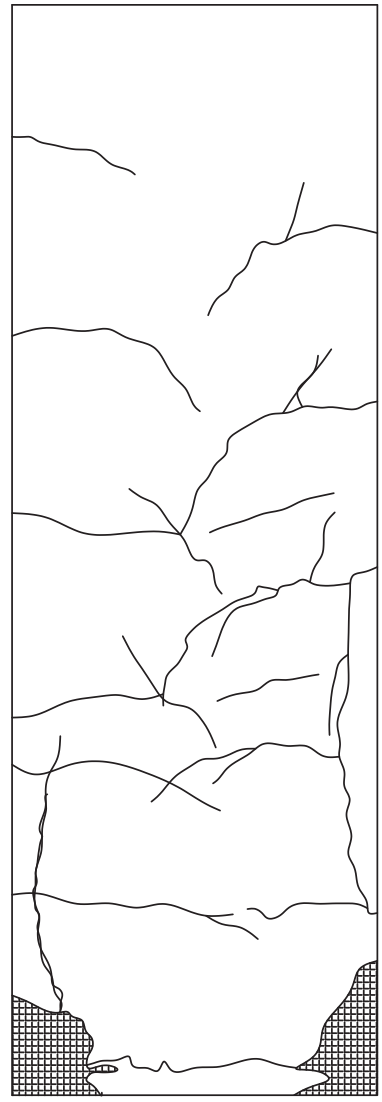

(e)

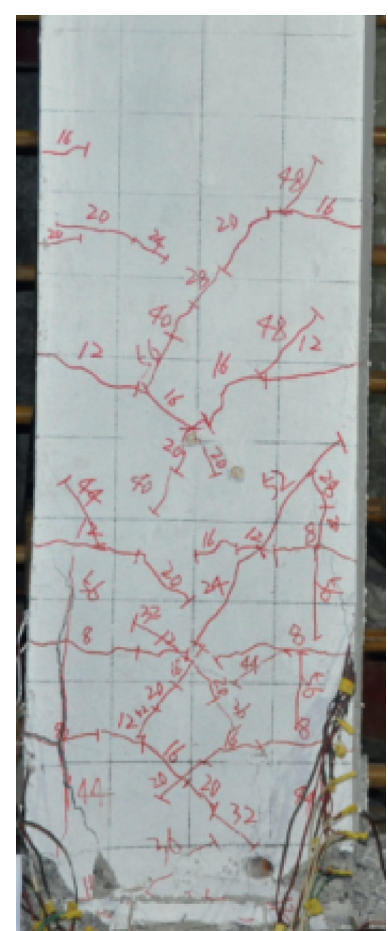

(c)

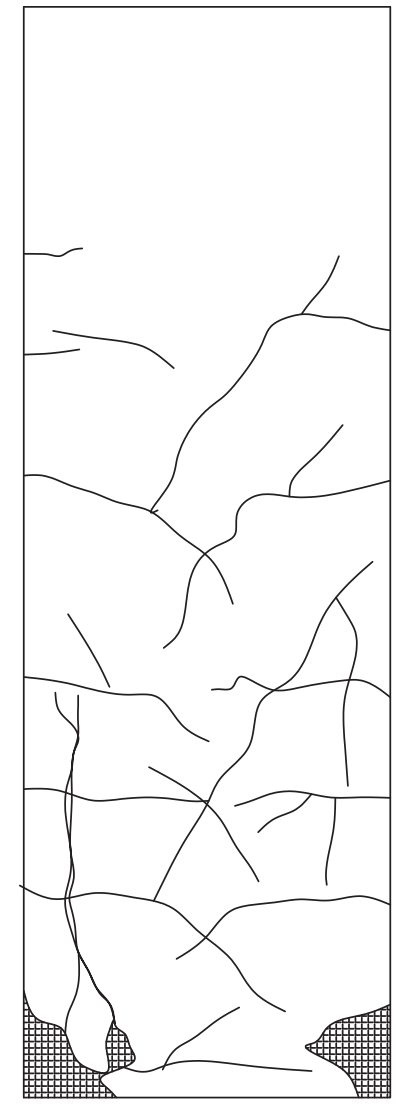

(f)

Figure 10: Pictures and illustrations of crack distribution of specimens at displacement limit state. (a) Picture of XZ1. (b) Picture of YZ1. (c) Picture of YZ2. (d) Crack illustration of XZ1. (e) Crack illustration of YZ1. (f) Crack illustration of YZ2. 

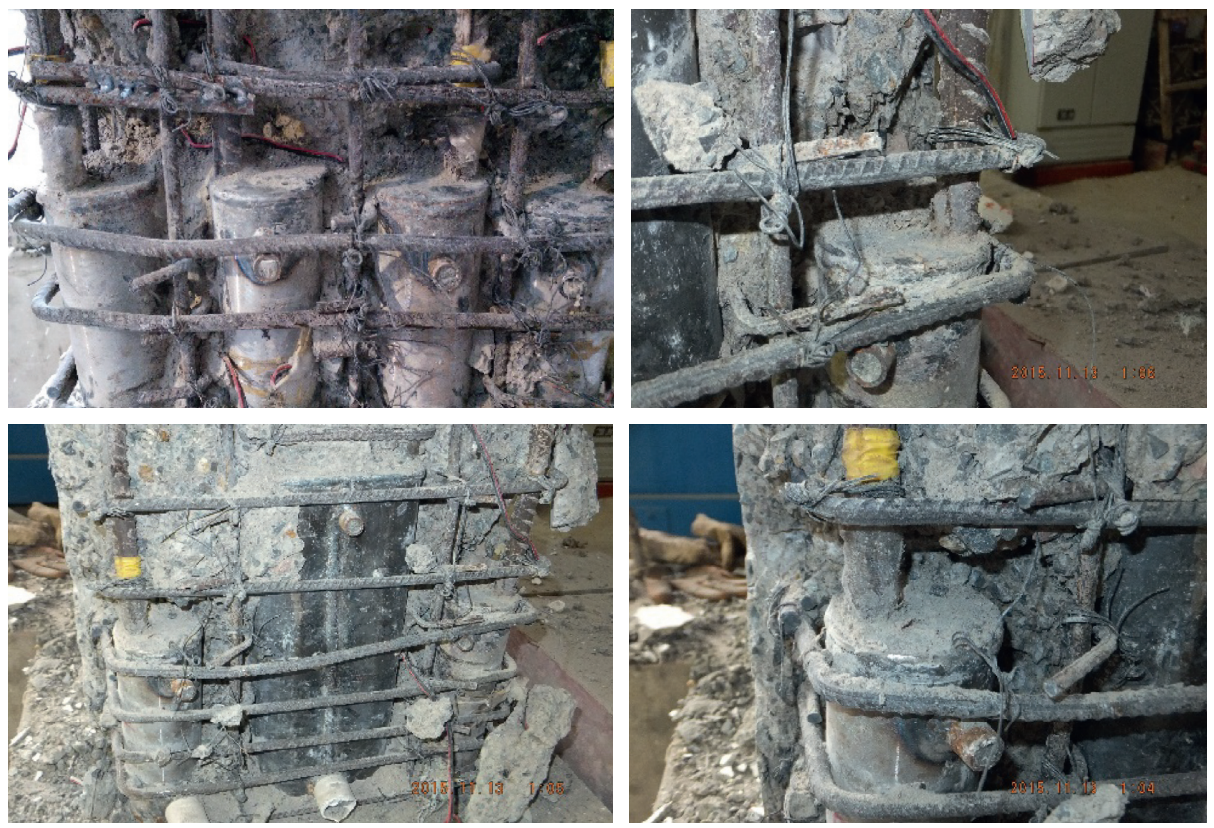

FIGURE 11: Pictures of joint regions after concrete being chiseled away.

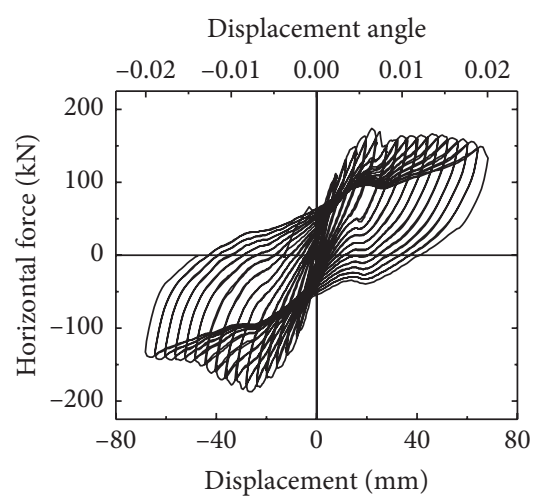

(a)

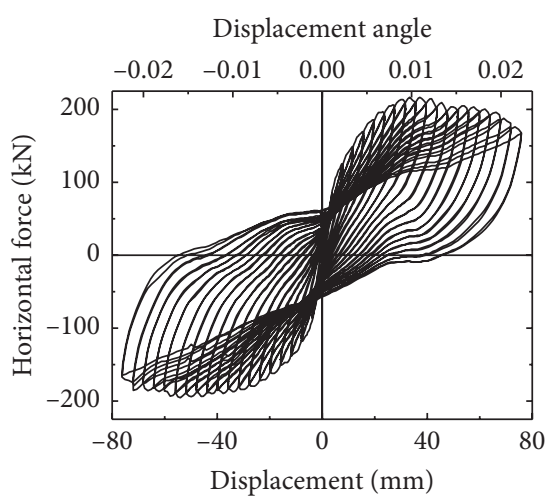

(b)

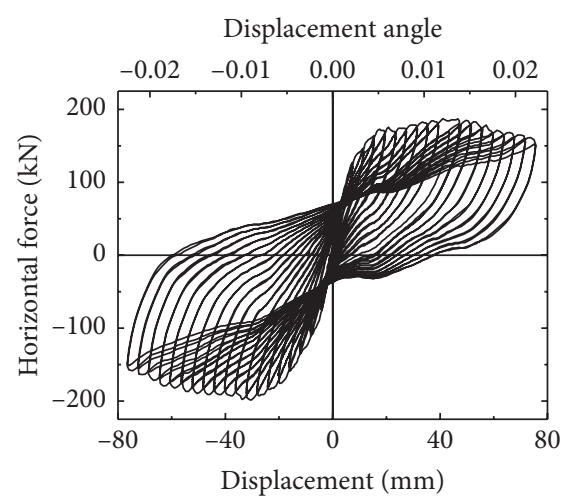

(c)

FIgure 12: Comparison of hysteresis curves. (a) Hysteresis curve of XZ1. (b) Hysteresis curve of YZ1. (c) Hysteresis curve of YZ2.

to tensile yield, the corresponding horizontal load was defined as the yield force $\left(F_{\mathrm{y}}\right)$. The maximum horizontal load that the column could withstand was defined as the peak force $\left(F_{\mathrm{p}}\right)$.

The cracking force $\left(F_{\mathrm{cr}}\right)$, the yield force $\left(F_{\mathrm{y}}\right)$, and the peak force $\left(F_{\mathrm{p}}\right)$ are shown in Table 6 . The cracking load of the precast columns was slightly higher than that of the cast-insitu column. This was because the sleeve had a restraining effect on the concrete. Since the sleeves in YZ2 were the longest, the restraining effect on the concrete was also the strongest, so the cracking load achieved the greatest value.

The yield loads and peak loads of the precast columns were higher than that of the cast-in-situ column. As the sleeves and the additional rebars and stirrups restrained the grout and concrete at the bottom of the precast columns, their compressive bearing capacity was enhanced. After the rebar yielded, the restraining effect reduced, thus the yield load was only slightly increased. However, this kind of restraining effect would become stronger at the peak load, so the peak load of the column increased significantly. It is noteworthy that the characteristic loads $\left(F_{\mathrm{cr}}, F_{\mathrm{y}}\right.$, and $\left.F_{\mathrm{p}}\right)$ of YZ1 in the positive direction were much greater than those in the negative direction, this might be caused by the nonsymmetrical section geometry and position of rebars.

According to the current Chinese concrete code [21], the horizontal force corresponding to the bearing capacity ultimate limit state of the column $\left(N_{\mathrm{u}}\right)$ was calculated according to the cast-in-situ column, in which the concrete cover thickness was deducted according to the actual situation. The ratios $F_{\mathrm{p}} / F_{\mathrm{pm}}$ were greater than 1.0 for both the precast columns, thus it was conservative to calculate the bearing capacity of precast columns according to the current code. Similarly, according to the current US 

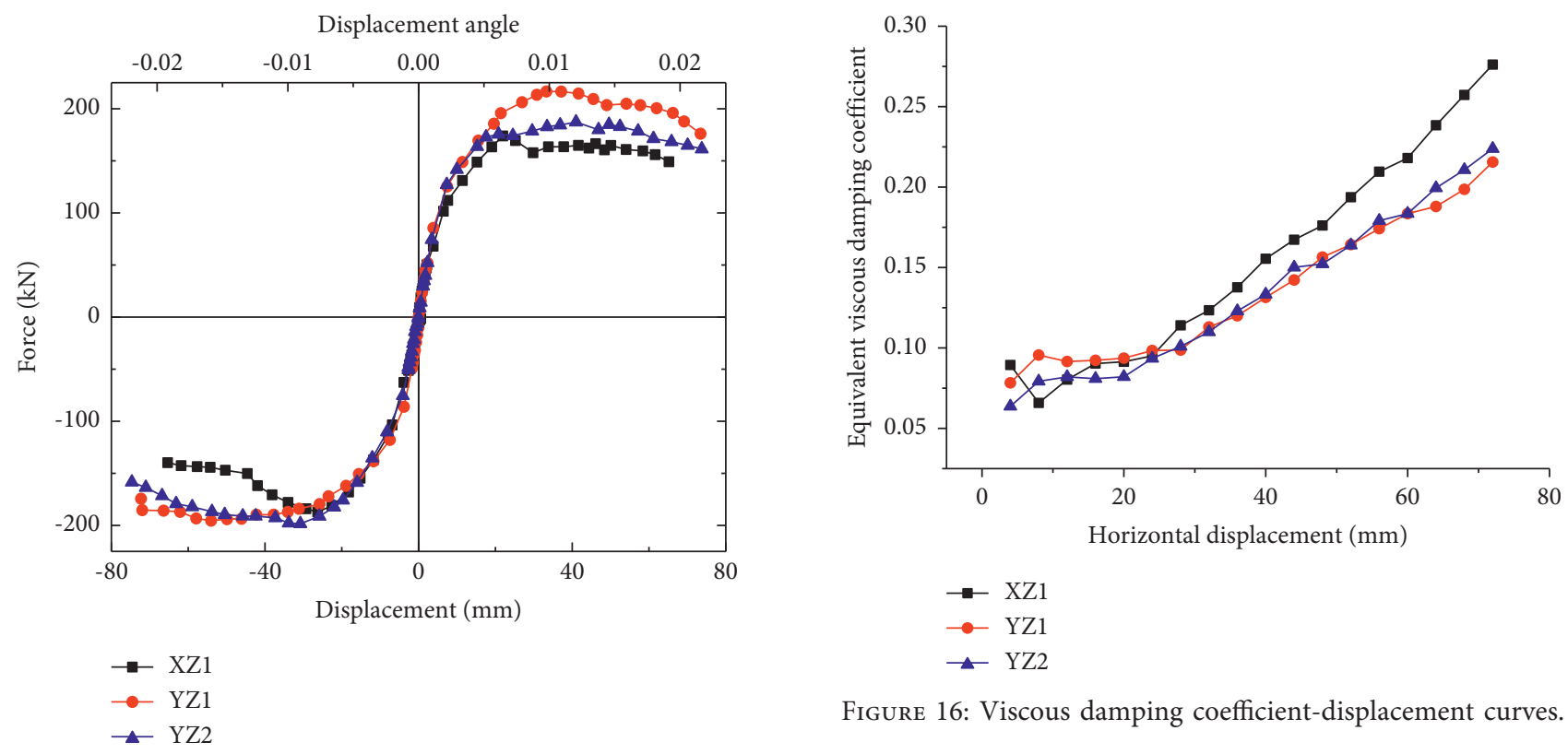

FIgURE 16: Viscous damping coefficient-displacement curves.

FIGURE 13: Comparison of skeleton curves.

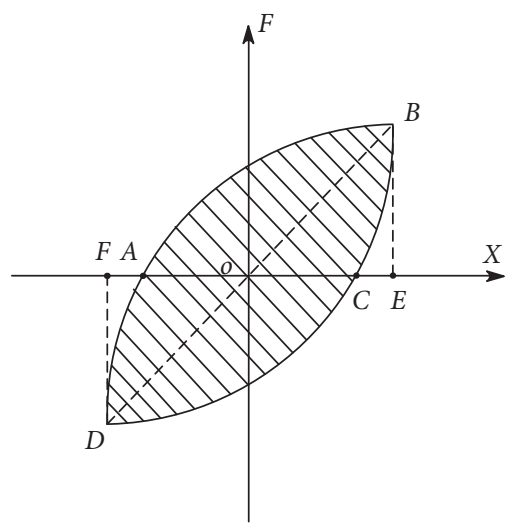

TABLe 5: Energy dissipation $(E)$ and equivalent viscous damping coefficient $(D)$ under the displacement limit state.

\begin{tabular}{lccccc}
\hline Specimen & $\Delta_{\mathrm{u}}(\mathrm{mm})$ & $E$ & $E_{i} / E_{1}$ & $D$ & $D_{i} / D_{1}$ \\
\hline $\mathrm{XZ1}$ & 66 & 13.99 & 1.00 & 0.23 & 1.00 \\
$\mathrm{YZ1}$ & 72 & 16.62 & 1.19 & 0.22 & 0.96 \\
$\mathrm{YZ2}$ & 70 & 16.16 & 1.16 & 0.23 & 1.00 \\
\hline
\end{tabular}

Note: $E_{i}$ and $D_{i}$ refer to the energy dissipations and equivalent viscous damping coefficients of YZ1 or YZ2, respectively, while $E_{1}$ and $D_{1}$ refer to those of XZ1.

Figure 14: Calculation of energy dissipation from force-displacement hysteresis curve.

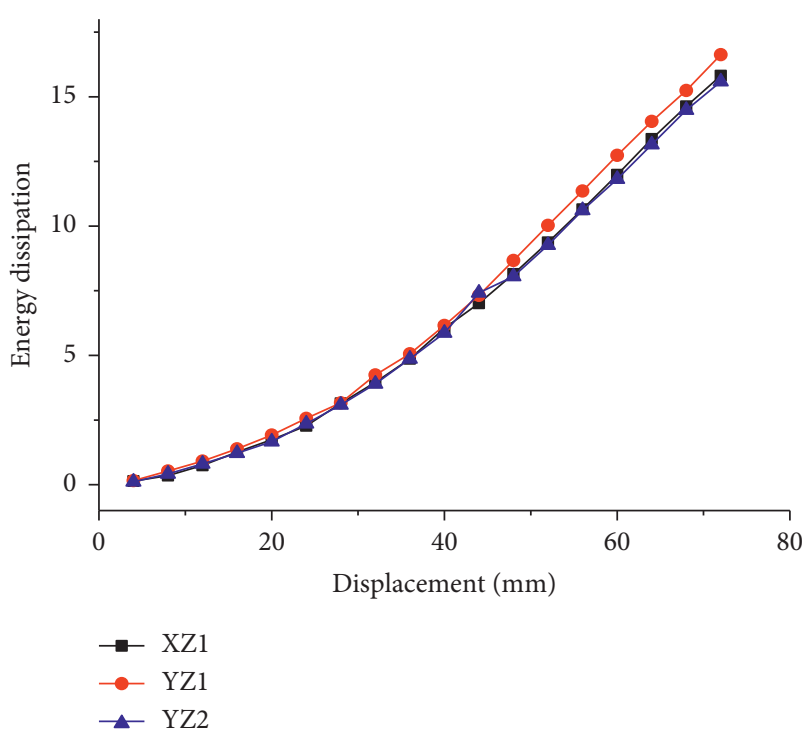

FIgURE 15: Energy consumption-displacement curves. concrete code [23], the calculated $F_{\mathrm{pm}}$ is also shown in Table 6. The US code is found to be more conservative than the Chinese code.

It can be seen from Table 6 that the bearing capacity of the precast columns was greater than that of the cast-in-situ column. When calculating the bearing capacity of the precast columns, the restraining effect of the sleeve on the grout could be considered [24] as follows:

$$
\begin{aligned}
& f_{c}=f_{c 1}+4 \sigma_{r}, \\
& \sigma_{r}=\frac{2 f_{y} A_{s s 1}}{s d_{\text {cor }}}=\frac{2 f_{y} t}{d_{\text {cor }}},
\end{aligned}
$$

where $f_{c 1}$ is the average compressive strength of grout and $f_{c 1}=77.98 \mathrm{MPa}, \sigma_{\mathrm{r}}$ is the radial pressure on the grout in the sleeve, and $f_{\mathrm{y}}, t$, and $d_{\text {cor }}$ are the yield strength, the wall thickness, and the inner diameter of the sleeve, respectively. Considering that type-II sleeve is not exactly circular, thus $\sigma_{\mathrm{r}}$ on the grout in it should be reduced with a factor of 0.75 . So $\sigma_{\mathrm{r}}$ is $34.67 \mathrm{MPa}$ for type-I sleeve, and $26.00 \mathrm{MPa}$ for type-II sleeve.

The ultimate bearing capacity $\left(N_{\mathrm{u}}\right)$ can be computed according to the Chinese code, "Code for Design of Concrete Structures (GB 50010-2010)," [21] as follows: 
TABLE 6: Comparison of horizontal force in different states of specimens.

\begin{tabular}{|c|c|c|c|c|c|c|c|c|c|c|c|}
\hline \multirow{2}{*}{ Specimen } & \multicolumn{3}{|c|}{$F_{\mathrm{cr}}(\mathrm{kN})$} & \multicolumn{3}{|c|}{$F_{\mathrm{y}}(\mathrm{kN})$} & \multicolumn{3}{|c|}{$F_{\mathrm{p}}(\mathrm{kN})$} & \multirow{2}{*}{$N_{\mathrm{u}}(\mathrm{kN})$} & \multirow{2}{*}{$F_{P} / N_{U}$} \\
\hline & $+F_{\mathrm{cr}}$ & $-F_{\mathrm{cr}}$ & Average & $+F_{\mathrm{y}}$ & $-F_{\mathrm{y}}$ & Average & $+F_{\mathrm{p}}$ & $-F_{\mathrm{p}}$ & Average & & \\
\hline $\mathrm{XZ1}$ & 101.6 & 103.1 & 102.3 & 159.3 & 153.3 & 156.3 & 173.9 & 187.2 & 180.5 & & $1.19(1.50)$ \\
\hline YZ1 & 122.2 & 86.1 & 104.2 & 179.9 & 141.9 & 160.9 & 216.5 & 195.5 & 206.2 & $152.2(120.6)$ & $1.35(1.71)$ \\
\hline YZ2 & 127.2 & 110.3 & 118.7 & 163.4 & 166.0 & 164.7 & 187.2 & 198.5 & 192.8 & & $1.27(1.60)$ \\
\hline
\end{tabular}

Note: the value in parentheses is calculated according to US ACI code, and that preceding the parentheses is calculated according to Chinese GB code.

$$
\left\{\begin{array}{l}
N_{u} \leq \alpha_{1} f_{c} b x+f_{y}^{\prime} A_{s}^{\prime}-f_{s} A_{s} \\
N_{u} e \leq \alpha_{1} f_{c} b x\left(h_{0}-\frac{x}{2}\right)+f_{y}^{\prime} A_{s}^{\prime}\left(h_{0}-a_{s}^{\prime}\right) \\
e=e_{i}+\frac{h}{2}-a_{2} \\
e_{i}=e_{0}+e_{a} \\
e_{a}=0.12\left(0.3 h_{0}-e_{0}\right)
\end{array}\right.
$$

where $\alpha_{1}$ is the coefficient of rectangular stress diagram and $\alpha_{1}=1.0 . f_{\mathrm{c}}$ is the axial compressive strength of concrete. $x$ is the depth of concrete compression zone. $f_{\mathrm{y}}$ and $f_{y}^{\prime}$ are the tensile strength and compressive strength of reinforcement, respectively. $A_{\mathrm{s}}$ and $A_{s}^{\prime}$ are the sectional areas of longitudinal reinforcement in tension and compression zones, respectively. $e$ is the distance between the axial force and the resultant force of the common tensile reinforcement. $e_{i}$ is the initial eccentricity. $e_{0}$ is eccentricity of the axial force to the section center of gravity. $e_{\mathrm{a}}$ is additional eccentricity. $h_{0}$ is effective depth of rectangular section. $a_{\mathrm{s}}$ and $a_{s}^{\prime}$ are the distances from the resultant force of the tensile reinforcement or the compressive reinforcement to the edge of the section, respectively.

The bearing capacity of all the specimens were calculated by the formula and are listed in Table 7 . The calculated values were less than the corresponding test values; this was because the tension and compression capacities of the sleeves were not considered.

The ultimate bearing capacity $\left(N_{\mathrm{u}}\right)$ can be computed according to the ACI code "Building Code Requirements for Structural Concrete and Commentary (ACI 318-1999)” [23] as follows:

$$
\left\{\begin{array}{l}
N_{u} \leq \gamma f_{c} b x+f_{y}^{\prime} A_{s}^{\prime}-f_{y} A_{s} \\
N_{u} e \leq \gamma f_{c} b x\left(\frac{h}{2}-\frac{x}{2}\right)+f_{y}^{\prime} A_{s}^{\prime}\left(\frac{h}{2}-a_{s}^{\prime}\right)+f_{y} A_{s}\left(h_{0}-\frac{h}{2}\right) \\
e=e_{i}+\frac{h}{2}-a_{s} \\
e_{i}=e_{0}+e_{a} \\
e_{a}=0.12\left(0.3 h_{0}-e_{0}\right)
\end{array}\right.
$$

where $\gamma$ is the difference coefficient of structure strength and specimen strength, and $\gamma=0.80$. The bearing capacities of all the specimens were also calculated and are compared in Table 7.

By comparing the ratios of $F_{P} / N_{u}$ in Tables 6 and 7, it can be found that for the precast specimens ( $Y Z 1$ and YZ2), the theoretical bearing capacities calculated with the consideration of the restraining effect provided by the sleeves are closer to the test values, so the influence of sleeve restraining should be considered in the design of precast columns. Secondly, by comparing the theoretical results computed according to Chinese and ACI design codes, it can be seen that the values calculated according to Chinese code are closer to the test value, i.e., that calculated according to ACI code are more conservative.

Since the difference between the $F_{P} / N_{u}$ ratios of the precast columns and the cast-in-situ column is negligible (1.21-1.27 for GB, and 1.52-1.62 for ACI), the design methods defined in the codes for the cast-in-situ column can be used to design the precast columns.

3.4. Deformation and Ductility. The vertex displacement angle can be defined as $\theta=\Delta / H$, where $\Delta$ is the horizontal displacement of the column top, and $H$ is the distance between the center of the loading beam and the top surface of the base beam. Table 8 lists the cracking displacement $\left(\Delta_{\mathrm{cr}}\right)$, yield displacement $\left(\Delta_{\mathrm{y}}\right)$, peak displacement $\left(\Delta_{\mathrm{p}}\right)$, and ultimate limit displacement $\left(\Delta_{\mathrm{u}}\right)$, as well as their corresponding vertex displacement angles $\left(\theta_{\mathrm{cr}}, \theta_{\mathrm{y}}, \theta_{\mathrm{p}}\right.$, and $\theta_{\mathrm{u}}$, respectively) of all the specimens. The displacement ductility coefficient can be defined as $\mu=\Delta_{u} / \Delta_{y}$.

It can be seen from Table 8 that the cracking and yield displacements of the precast columns were similar to that of the cast-in-situ column, and the peak displacement, ultimate displacement, and ductility coefficient were larger than that of the cast-in-situ column.

The cracking displacement angles $\left(\theta_{\mathrm{cr}}\right)$ of the precast columns were $1 / 314$ and $1 / 219$ for $\mathrm{YZ1}$ and YZ2, respectively, which were much greater than the displacement angle limit of 1/550 for the elastic analysis of frame structures provided in the Chinese code, "Code for Seismic Design of Buildings (GB50011-2010)" [25]. It indicates that under minor earthquakes, when a precast frame structure meets the limit value of the displacement angle between the elastic layers, the precast columns will not crack and will be still in the elastic stage.

The ultimate displacement angle $\left(\theta_{\mathrm{u}}\right)$ of the precast columns were $1 / 23$ and $1 / 24$ for YZ1 and YZ2, respectively, which were greater than that of the cast-in-situ column 
TABLE 7: Comparisons between test and theoretical bearing capacities $(\mathrm{kN})$.

\begin{tabular}{lcccc}
\hline Specimen & Test value $F_{\mathrm{p}}$ & Theoretical value $N_{\mathrm{u}}$ according to GB & Theoretical value $N_{\mathrm{u}}$ according to ACI & $F_{\mathrm{p}} / N_{\mathrm{u}}$ calculation error \\
\hline $\mathrm{XZ1}$ & 180.5 & 147.9 & $(116.1)$ & $1.22(1.55)$ \\
$\mathrm{YZ1}$ & 206.2 & 162.6 & $(127.4)$ & $1.27(1.62)$ \\
$\mathrm{YZ2}$ & 192.8 & 160.0 & $(126.9)$ & $1.21(1.52)$ \\
\hline
\end{tabular}

Note: the value in parentheses is calculated according to US ACI code, and that preceding the parentheses is calculated according to Chinese GB code.

TABLE 8: Deformation indicators of the specimens at the major characteristic states $(\mathrm{mm})$.

\begin{tabular}{|c|c|c|c|c|c|c|c|c|c|c|c|c|c|c|c|}
\hline \multirow{2}{*}{ Specimen } & \multicolumn{3}{|c|}{$\Delta_{\mathrm{cr}}\left(\theta_{\mathrm{cr}}{ }^{*}\right)$} & \multicolumn{3}{|c|}{$\Delta_{\mathrm{y}}\left(\theta_{\mathrm{y}}{ }^{*}\right)$} & \multicolumn{3}{|c|}{$\Delta_{\mathrm{p}}\left(\theta_{\mathrm{p}}{ }^{*}\right)$} & \multicolumn{3}{|c|}{$\Delta_{\mathrm{u}}\left(\theta_{\mathrm{u}}{ }^{*}\right)$} & \multicolumn{3}{|c|}{$\mu$} \\
\hline & $+F$ & $-F$ & Average & $+F$ & $-F$ & Average & $+F$ & $-F$ & Average & $+F$ & $-F$ & Average & $+F$ & $-F$ & Average \\
\hline \multirow{2}{*}{ XZ1 } & 6.47 & 6.49 & 6.48 & 17.55 & 18.76 & 18.16 & 21.95 & 26.27 & 24.11 & 66.26 & 42.51 & 54.39 & \multirow{2}{*}{3.78} & \multirow{2}{*}{2.27} & \multirow[b]{2}{*}{3.00} \\
\hline & $1 / 263^{*}$ & $1 / 262^{*}$ & $1 / 262^{*}$ & $1 / 97^{*}$ & $1 / 91^{*}$ & $1 / 94^{*}$ & $1 / 77^{*}$ & $1 / 65^{*}$ & $1 / 71^{*}$ & $1 / 26^{*}$ & $1 / 40^{*}$ & $1 / 31^{*}$ & & & \\
\hline \multirow{2}{*}{ YZ1 } & 7.04 & 3.8 & 5.42 & 17.21 & 12.29 & 14.75 & 33.28 & 54.02 & 43.65 & 69.15 & 76.31 & 72.73 & \multirow{2}{*}{4.02} & \multirow{2}{*}{6.21} & \multirow{2}{*}{4.93} \\
\hline & $1 / 241^{*}$ & $1 / 447^{*}$ & $1 / 314^{*}$ & $1 / 99^{*}$ & $1 / 138^{*}$ & $1 / 115^{*}$ & $1 / 51^{*}$ & $1 / 31^{*}$ & $1 / 39^{*}$ & $1 / 25^{*}$ & $1 / 22^{*}$ & $1 / 23^{*}$ & & & \\
\hline \multirow{2}{*}{ YZ2 } & 7.34 & 8.22 & 7.78 & 14.95 & 17.09 & 16.02 & 40.99 & 30.79 & 35.89 & 73.74 & 66.8 & 70.27 & & \multirow{2}{*}{3.91} & \multirow{2}{*}{4.39} \\
\hline & $1 / 232^{*}$ & $1 / 207^{*}$ & $1 / 219^{*}$ & $1 / 114^{*}$ & $1 / 99^{*}$ & $1 / 106^{*}$ & $1 / 41^{*}$ & $1 / 55^{*}$ & $1 / 47^{*}$ & $1 / 23^{*}$ & $1 / 25^{*}$ & $1 / 24^{*}$ & & & \\
\hline
\end{tabular}

Note: the figures marked with asterisk $\left(^{*}\right)$ are the corresponding vertex displacement angles.

$(1 / 31)$, and much greater than the elastic-plastic displacement angle limit of $1 / 50$ for frame structures stipulated in the Chinese seismic code [25], indicating that under major earthquakes, when a precast frame structure with the type-I or type-II connectors reaches the elastic-plastic interstory displacement angle limit (i.e., $\theta=1 / 50$ ), there will still be sufficient safety margin $(1 / 50<<1 / 24)$.

The peak displacement $\left(\Delta_{\mathrm{y}}\right)$, ultimate displacement $\left(\Delta_{\mathrm{u}}\right)$, and ductility coefficient $(\mu)$ of the precast columns were greater than that of the cast-in-situ column. The reason for this phenomenon was that the upper and lower rebars in the grouted sleeve lapping connector joints were not in a straight line, which would cause eccentricity, so the deformation was greater than the axial tensile rebars. At the same time, the additional stirrups restrained the concrete in compression zone, thus the bearing capacity of the precast columns decreased more slowly.

3.5. Stiffness. The secant stiffness $K_{i}$ represents the stiffness of the frame column and is defined as the secant stiffness of the maximum displacement per cycle under reciprocating loads, calculated as follows:

$$
K_{i}=\frac{\left|+F_{i}\right|+\left|-F_{i}\right|}{\left|+\Delta_{i}\right|+\left|-\Delta_{i}\right|}
$$

where $\left|+F_{i}\right|$ and $\left|-F_{i}\right|$ are the absolute values of the peak loads in the positive and negative directions of the $i$-th cycle and $\left|+\Delta_{i}\right|$ and $\left|-\Delta_{i}\right|$ are the absolute values of the displacements corresponding to the peak loads.

Figure 17 shows the degradation of secant stiffness $\left(K_{i}\right)$ for the specimens. Before the displacement reached $15 \mathrm{~mm}$, the stiffness of the three columns decreased rapidly, but then the reduction rate decreased gradually. However, under the same displacement conditions, the stiffness of the precast columns was slightly greater than that of the cast-in-situ column, which was mainly beneficial from the sleeves that increased the stiffness of the precast columns.
Table 9 shows the cracking, yielding, peak, and ultimate stiffness of the three columns. The cracking and yielding stiffness of the precast columns was greater than that of the cast-in-situ column, but the peak stiffness and ultimate stiffness were slightly smaller. This indicates that the sleeves in the precast columns had a positive influence on the column stiffness at the early stage of loading, in which the columns' cross-sections were intact. However, the eccentricity of rebars, and thus the rotation of the grouted sleeve lapping connectors, resulted in a considerable loss of column stiffness after the restraining from the surrounding concrete disappeared in the later stage of loading.

3.6. Distribution of Horizontal Displacement. Figure 18 shows the distribution of horizontal displacement of all the columns in the crack state, yield state, peak state, and displacement limit state. It can be seen from the figure that the horizontal displacement of the columns increased sequentially with the change of load state.

The horizontal displacement was distributed in a bending-shear shape along the height of the columns, which indicated that the flexural deformation of the column was concentrated within the lower range at the bottom of the column. The displacement outside this range was almost linearly distributed.

The distributions of horizontal displacements in the positive and negative directions were generally symmetrical in the early stage of loading, but they had a significant asymmetry in the later stage, especially for the specimen YZ1. This may be caused by the asymmetric geometry of the column cross section due to construction error and the insufficient compacting of concrete pouring on the right side of the column, where the strain gauge wires were located.

Comparing Figures 18(a)-18(c), it can be seen that the peak displacement and ultimate limit displacement of the precast columns (YZ1 and YZ2) were greater than that of the cast-in-situ column (XZ1), which indicates that the 


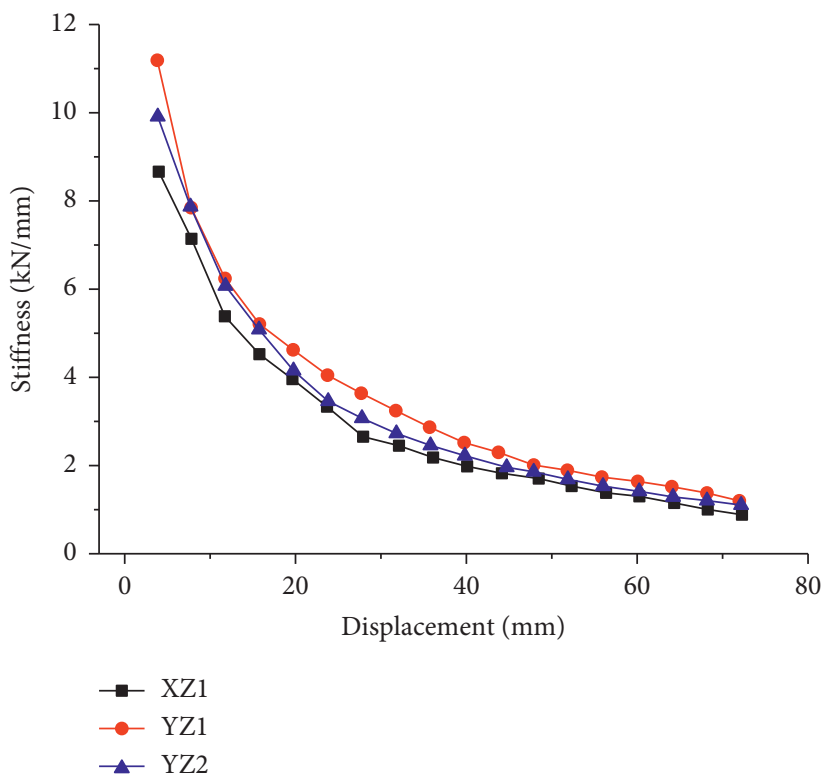

FIgure 17: Stiffness degradation curves.

Table 9: Secant stiffness of the specimens at the major characteristic states $(\mathrm{kN} / \mathrm{mm})$.

\begin{tabular}{lcccc}
\hline Specimen & Cracking state & Yielding state & Peak state & Displacement limit state \\
\hline XZ1 & 15.79 & 8.61 & 7.49 & 2.84 \\
YZ1 & 19.22 & 10.91 & 4.72 & 2.44 \\
YZ2 & 15.26 & 10.28 & 5.37 & 2.37 \\
\hline
\end{tabular}

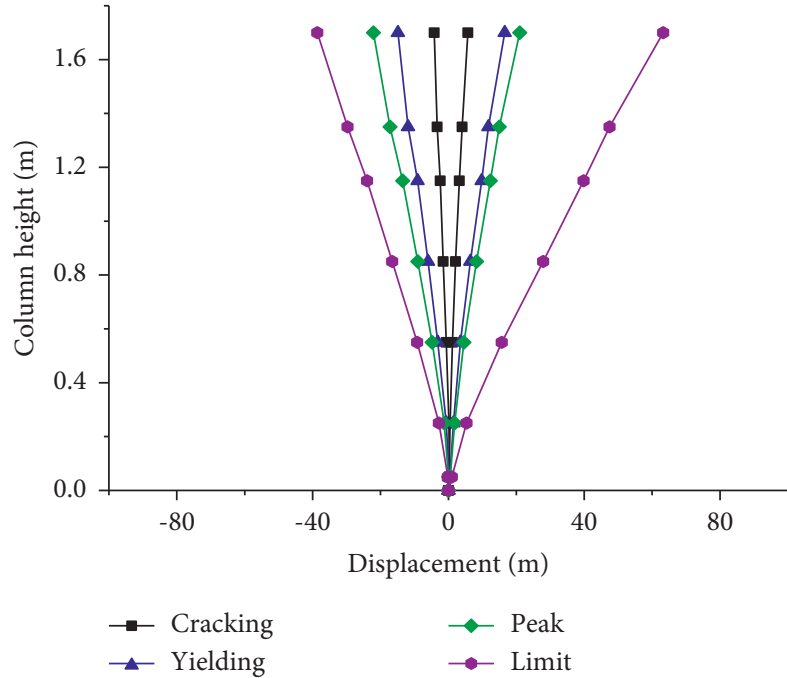

(a)

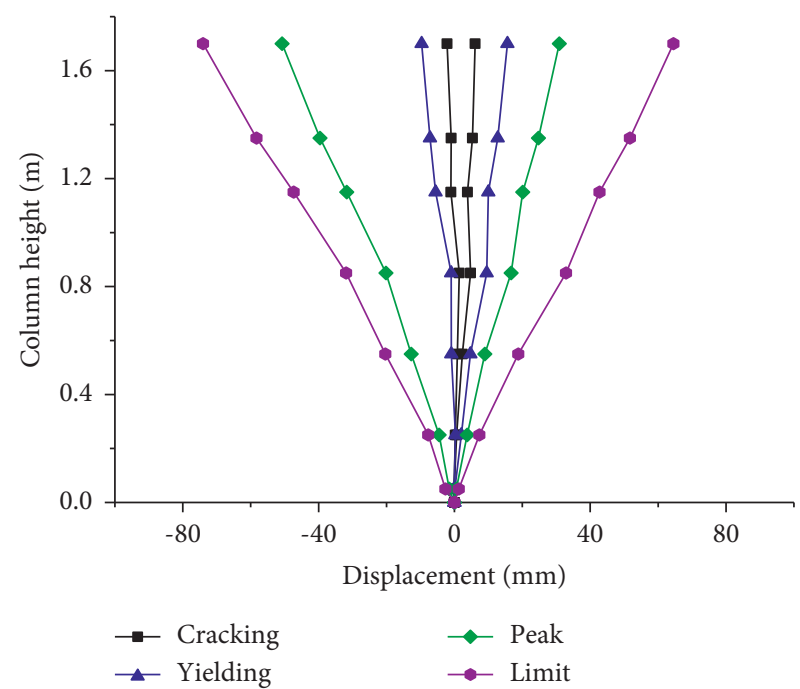

(b)

Figure 18: Continued. 


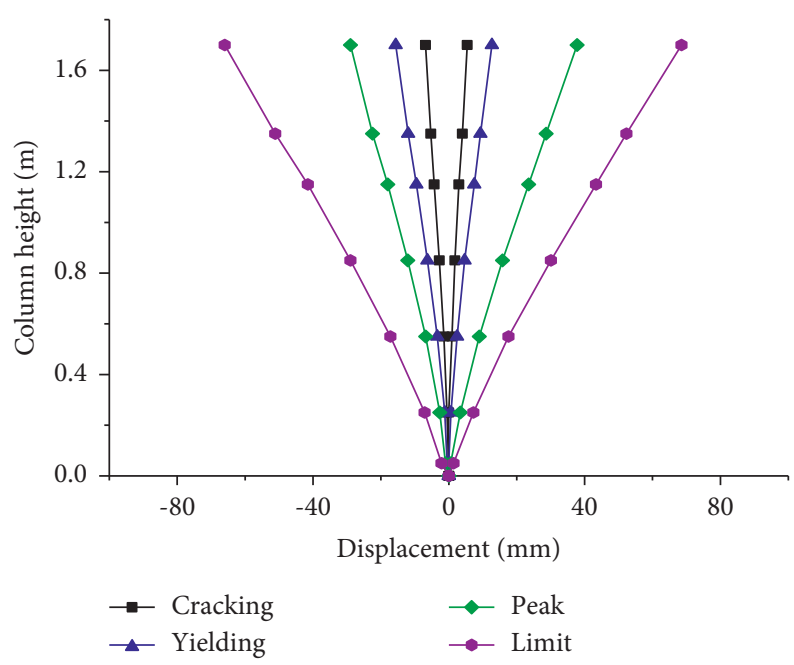

(c)

Figure 18: Distribution of horizontal displacement. (a) XZ1. (b) YZ1. (c) YZ2.

deformation capacity of the precast columns was greater in the later stage of loading.

3.7. Reinforcement Strain. The yielding strain of the rebar was tested to be $2470 \mathrm{u} \varepsilon$. Because the strain of the rebar had a poor correlation with the horizontal force after yielding, the maximum strain was set to $3000 \mathrm{u} \varepsilon$ to analyze the relationship between the strain and the horizontal force. The tensile strain was recorded as a positive value, and the compressive strain was negative.

Figure 19 shows the hysteresis curve and skeleton curve between the horizontal force and the strain of the rebar at the right side of the cast-in-situ column XZ1 at the position of $20 \mathrm{~mm}$ from the top surface of the base beam. The negative hysteresis curve of the rebar was plump, while the rebar had a narrow hysteresis curve and small area under tension. It was evident from the skeleton curve that the maximum tensile strain of the rebar was greater than the maximum strain under compression. The tensile strain of this rebar (occurring when the load was in the negative direction) increased rapidly with the horizontal force, while the compressive strain (occurring when the load was in the positive direction) changed slowly. This was because the rebars withstood almost all the tensile force, while the rebar and concrete resisted the compression force together.

Figures 20 and 21 are the horizontal force-strain hysteresis curve and skeleton curve for the strain gauges on the upper rebars (20 $\mathrm{mm}$ above the type-I/type-II sleeve) and the lower rebars $(20 \mathrm{~mm}$ above the base beam, i.e., in the lower end of the sleeve) on the right side of the columns YZ1 and YZ2, respectively. When the rebar was under compression, the compressive strain above the upper rebar was generally greater than that of the lower rebar (SG20 > SG4), and the corresponding hysteresis curves were plumper as well. This was because the compressive stress transmitted by the upper rebar alone, while it was withstood by the sleeve, the grout, and the lower rebar together. When the rebar was under

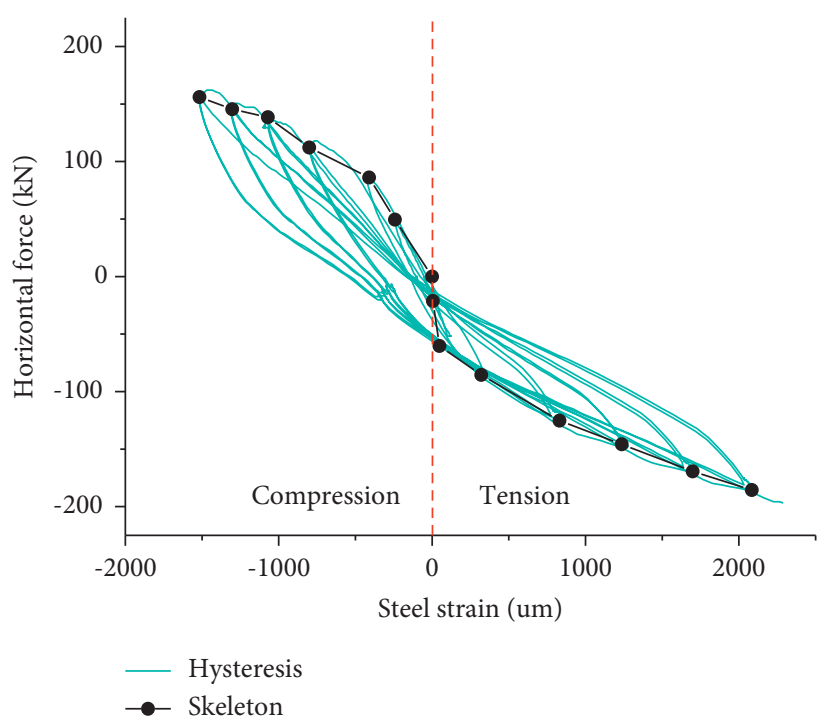

FIgURE 19: Hysteresis and skeleton curves of rebar strain in XZ1.

tension, the force-strain hysteresis curves of the upper and lower rebars were consistent; this was because the sleeve and grout cannot transfer tensile stress effectively. Since the bending moment of the column above the sleeve caused by the horizontal force was relatively small compared to that below the sleeve, the tensile strain of the upper rebar was smaller than that of the lower rebar.

3.8. Sleeve Transverse Strain. The sleeve transverse strain was composed of two parts: (1) the circumferential tension induced by the expansion of the grout and (2) the strain caused by the axial tension or compression of the sleeve due to the Poisson's ratio effect.

Figure 22 shows the transverse strains in the middle of the type-I sleeve on the right side of ColumnYZ1. The strain near the rebar location (SG14) was generally greater than the 


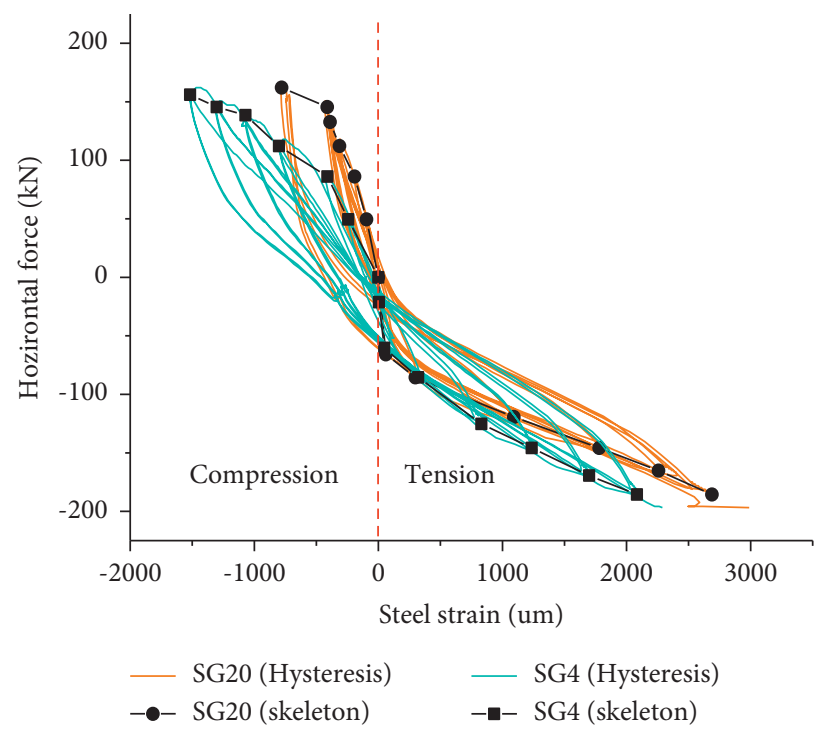

FIGURE 20: Hysteresis and skeleton curves of rebar strains above and below the type-I sleeve in YZ1.

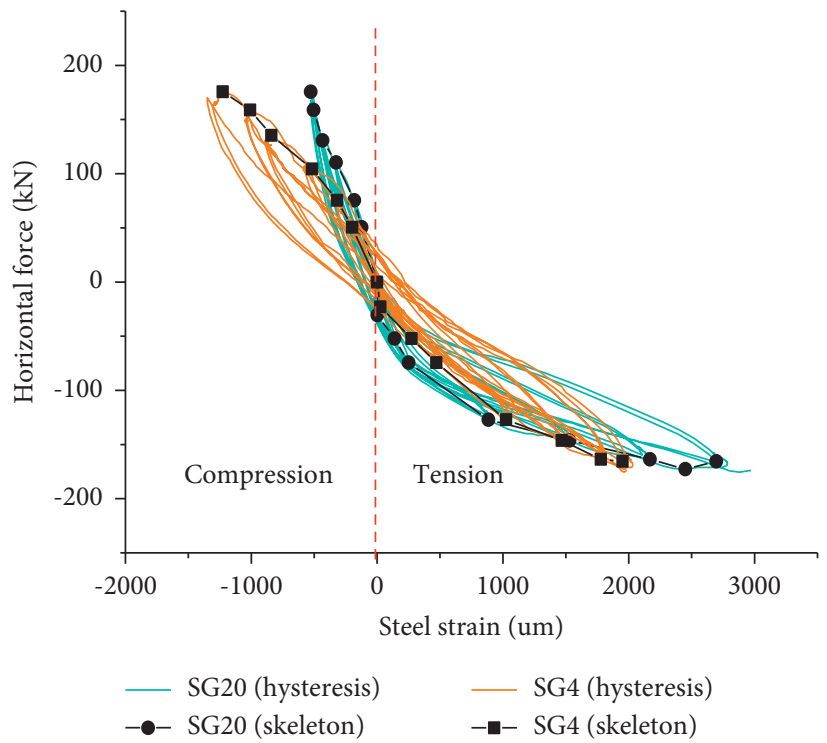

FIgURE 21: Hysteresis and skeleton curves of rebar strains above and below the type-II sleeve in YZ2.

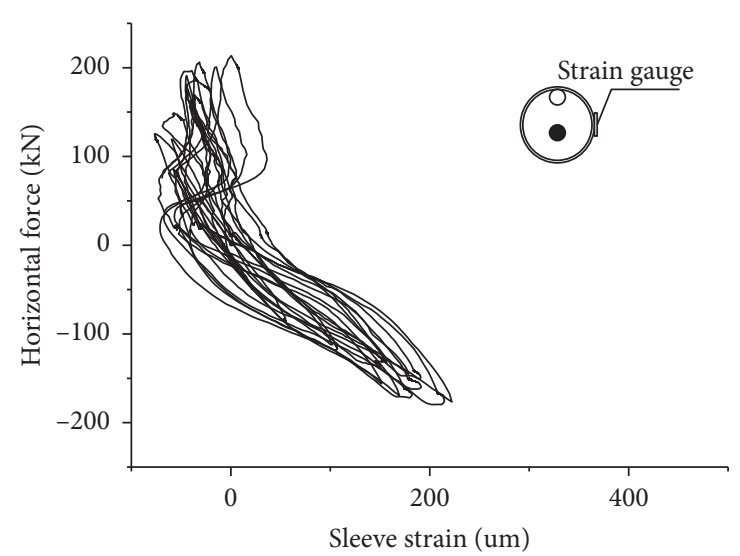

(a)

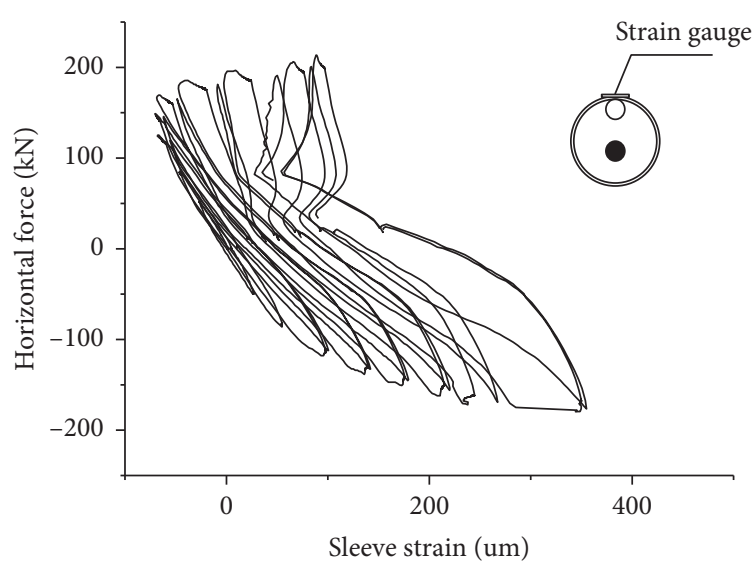

(b)

Figure 22: Hysteresis curves for transverse strains of type-I sleeve in YZ1. (a) Strain gauge away from the rebar (SG15). (b) Strain gauge near the rebar (SG16). 


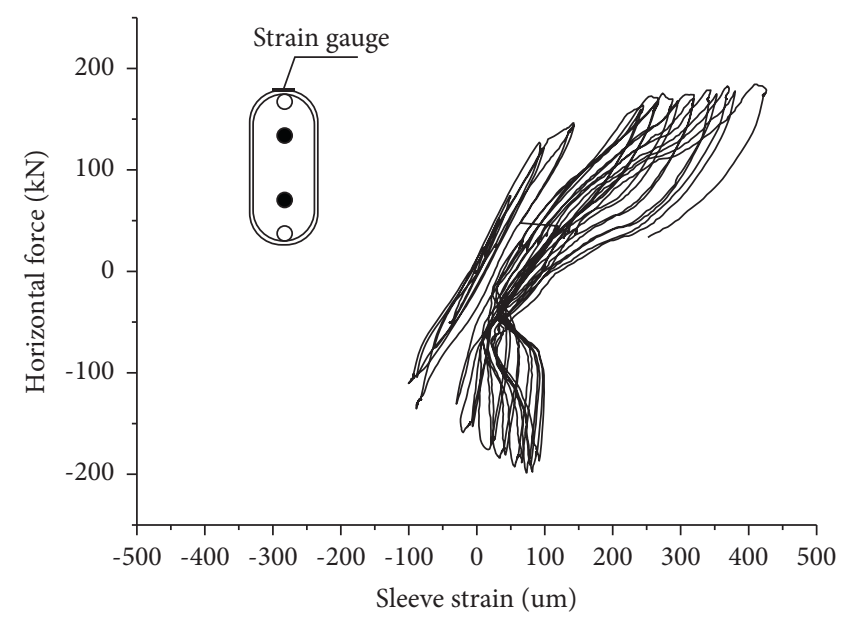

(a)

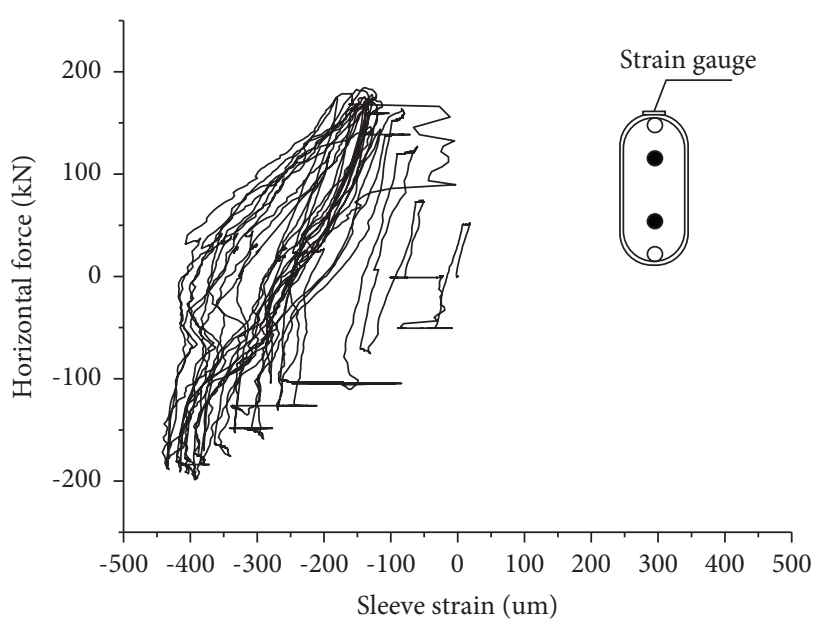

(b)

Figure 23: Hysteresis curves for transverse strain of type-II sleeve in YZ2. (a) Strain gauge near the rebar (SG12). (b) Strain gauge near the rebar (SG16).

TABLE 10: Transverse strain of type-I sleeve in YZ1 at the peak state $(\mu \varepsilon)$.

\begin{tabular}{lcccccccccc}
\hline \multirow{2}{*}{ Direction } & \multicolumn{4}{c}{ Left side of column } & \multicolumn{3}{c}{ Right side of column } \\
& SG9 & SG10 & SG11 & SG12 & Average & SG13 & SG14 & SG15 & SG16 & Average \\
\hline$+F_{\mathrm{p}}$ & 254 & -13 & 813 & 913 & 492 & 11 & 277 & 97 & 21 & 101 \\
$-F_{\mathrm{p}}$ & -7 & -376 & 122 & 841 & 145 & - & - & 488 & 415 \\
\hline
\end{tabular}

Note: "-" indicates that the strain gauge was damaged in the peak state and no valid data were obtained.

strain far from the rebar location (SG13). When the horizontal load was in the negative direction, the rebar in this sleeve was under tension, thus the transverse strain of the sleeve was caused by the expansion of grout and was positive. When the horizontal load was positive, the rebar, sleeve, and surrounding concrete were all in compression: (1) when the horizontal force was small, the rigidity of the rebar and sleeve was large, and the elastic modulus of the concrete around the sleeves was small; therefore, the lateral expansion of concrete caused by compression was higher than that of the sleeve. The concrete will squeeze the sleeve, so the circumferential strain of the sleeve became negative. (2) When the horizontal load was continuously increased, the concrete around the sleeve was gradually destroyed, and the sleeve and the internal grouting material expand laterally, which made the sleeve transverse strain become positive.

Figure 23 shows the transverse strains in the middle of the type-II sleeves on the left and right sides of Column YZ2. The strains of tensile and compressive sleeves were generally the same, which indicated that the sleeves had a poor constraint on the grout.

Table 10 shows the lateral strains of the type-I sleeves in column YZ1 under the peak state. Tables 11 and 12 show the lateral strains of the type-I and type-II sleeves, respectively, in column YZ2 under the peak state. It was evident that most of the sleeves were in tension in the circumferential direction, that is, the expansion of the grout volume played a dominant role in the sleeve transverse strain. The maximum magnitude of the circumferential strains was less than 1000
TABLE 11: Transverse strain of type-I sleeve in YZ2 at the peak state $(\mu \varepsilon)$.

\begin{tabular}{lcccccc}
\hline Direction & \multicolumn{2}{c}{$\begin{array}{c}\text { Left side of } \\
\text { column }\end{array}$} & Average & \multicolumn{4}{c}{$\begin{array}{c}\text { Right side of } \\
\text { column }\end{array}$} & Average \\
& SG9 & SG10 & & SG13 & SG14 & \\
\hline$+F_{\mathrm{p}}$ & 306 & 447 & 377 & - & 894 & 894 \\
$-F_{\mathrm{p}}$ & 53 & 506 & 280 & 514 & 96 & 305 \\
\hline
\end{tabular}

Note: “-" indicates that the strain gauge was damaged in the peak state and no valid data were obtained.

TABLE 12: Transverse strain of type-II sleeve in YZ2 at the peak state $(\mu \varepsilon)$.

\begin{tabular}{lcccccc}
\hline Direction & \multicolumn{2}{c}{$\begin{array}{c}\text { Left side of } \\
\text { column }\end{array}$} & Average & \multicolumn{4}{c}{$\begin{array}{c}\text { Right side of } \\
\text { column }\end{array}$} & Average \\
& SG11 & SG12 & & SG15 & SG16 & \\
\hline$+F_{\mathrm{p}}$ & 226 & 367 & 296 & - & -129 & -129 \\
$-F_{\mathrm{p}}$ & 290 & 858 & 574 & 74 & -392 & -159 \\
\hline
\end{tabular}

Note: “-" indicates that the strain gauge was damaged in the peak state and no valid data were obtained.

$\mu \varepsilon$, i.e., is less than the yield strain of steel, which indicated that the sleeves were in satisfactory working condition.

\section{Conclusions}

Through the quasi-static test of a cast-in-situ column and two precast columns, of which the longitudinal reinforcements were connected by type-I and type-II grouted sleeve lapping connectors, the following conclusions can be drawn: 
(1) The initial horizontal cracks of the cast-in-situ column occurred at the bottom of the column, and that of the precast columns occurred above the top end of sleeves, for the sleeves provided considerable restraining, thus reduced the longitudinal strain of concrete and prevented the concrete from cracking horizontally. The concrete cover outside the sleeves did not fall off in this test because of the additional vertical rebars and stirrups, and no slippage between the concrete/grout and the reinforcing steel/sleeves was found.

(2) The cracking, yielding, and peak loads of the precast columns were higher than that of the cast-in-situ column. This is because the sleeves, grout, and the additional rebars shared the force transfer with the steel reinforcement, and the additional stirrups provided confinement to the concrete.

(3) The cracking and yield displacements of all the columns were analogous, and the crack displacement angles of the precast columns were $1 / 314$ and $1 / 219$, which satisfy the requirement of the Chinese code (1/ 550). The peak and ultimate displacements, as well as the ductility coefficients of the precast columns, were larger than that of the cast-in-situ column, and the ultimate displacement angles of the precast columns were $1 / 23$ and $1 / 24$, which were larger than $11 / 50$ required by the Chinese code.

(4) The precast columns had greater cracking and yielding stiffness but smaller peak stiffness than the cast-in-situ column, which indicates the sleeves had a positive influence on stiffness when the cross section was intact, but the eccentricity of rebars in the grouted sleeve lapping connectors reduced the column stiffness in the later stage of loading.

(5) Because the additional rebars and stirrups confined the concrete in the joint core zone and thus delayed concrete crash, the energy consumption of the precast columns was slightly better than that of the cast-in-situ column in the displacement limit state.

(6) The type-I and type-II sleeves transferred steel stress of rebars satisfactorily under the peak load, and the circumferential strain of the sleeves was smaller than the yield strain of steel material; thus, the sleeves were in satisfactory working condition.

(7) Due to the limited number of specimens and range of parameters investigated in this study, more experimental and numerical studies would be beneficial for a further understanding of the force transfer mechanism of the grouted sleeve lapping connectors. However, the test results provide benchmark data for further numerical and theoretical studies on this connecting technique, as well as guidelines for the design and practice of precast frame structure.

\section{Data Availability}

Data available upon request to the corresponding author.

\section{Conflicts of Interest}

The authors declare that they have no conflicts of interest.

\section{Acknowledgments}

This study was financially supported by the National Natural Science Foundation of China (Grant no. 51578228), which is gratefully acknowledged. And, thanks are due to Prof. LV Xilin (University of Tongji) for his assistance.

\section{References}

[1] A. A. Sayadi, A. B. A. Rahman, M. Z. B. Jumaat, A. U. Johnson, and S. Ahmad, "The relationship between interlocking mechanism and bond strength in elastic and inelastic segment of splice sleeve," Construction and Building Materials, pp. 55227-55237, 2014.

[2] E. Henin and G. Morcous, "Non-proprietary bar splice sleeve for precast concrete construction," Engineering structures, vol. 83, pp. 83154-83162, 2015.

[3] M. Abukawa, "Grouted splicing sleeve connector for re-bar in precast concrete units," Patent US5392582-A, 1992.

[4] A. Alias, M. A. Zubir, K. A. Shahid, and A. B. A. RAhman, "Structural performance of grouted sleeve connectors with and without transverse reinforcement for precast concrete structure," Procedia Engineering, vol. 53, pp. 53116-53123, 2013.

[5] J. A. H. Seyed and B. A. R. Ahmad, "Analysis of spiral reinforcement in grouted pipe splice connectors," Građevinar, vol. 65, pp. 65537-65546, 2013.

[6] A. A. Sayadi, A. B. Abd Rahman, A. Sayadi, M. Bahmani, and L. Shahryari, "Effective of elastic and inelastic zone on behavior of glass fiber reinforced polymer splice sleeve," Constrution and Building Materials, vol. 80, pp. 8038-8047, 2015.

[7] S. J. A. Hosseini, A. B. Abd Rahman, M. H. Osman, A. Saim, and A. Adnan, "Bond behavior of spirally confined splice of deformed bars in grout," Constrution and Building Materials, vol. 80, pp. 80180-80194, 2015.

[8] Z. B. Haber, M. S. Saiidi, and D. H. Sanders, "Seismic performance of precast columns with mechanically spliced column-footing connections," ACI Structural Journal, vol. 111, pp. 639-650, 2014.

[9] J. H. Ling, A. B. A. Rahman, and I. S. Ibrahim, "Feasibility study of grouted splice connector under tensile load," Constrution and Building Materials, vol. 50, pp. 50530-50539, 2014.

[10] A. Einea, T. Yamane, and M. K. Tadros, "Grout-filled pipe splices for precast concrete construction," PCI Journal, vol. 40, pp. 4082-4093, 1995.

[11] P. Riva, "Seismic behaviour of precast column-to-foundation grouted sleeve connections," in Advances in Engineering Structures, Mechanics \& Construction, M. Pandey, W. Xie, and L. Xu, Eds., Springer, Dordrecht, Netherlands, 2006.

[12] C. O. Yu, H. Alrasyid, Z. B. Haber, and J. L. Huang, "Cyclic behavior of precast high-strength reinforced concrete columns," ACI Structural Journal, vol. 112, no. 6, Article ID 112839, 2015.

[13] Z. Wang, H. Qu, T. Li et al., "Quasi-static cyclic tests of precast bridge columns with different connection details for high seismic zones," Engineering Structures, vol. 158, pp. 1581315827, 2018.

[14] M. J. Ameli, J. E. Parks, D. N. Brown, and C. P. Pantelides, "Seismic evaluation of grouted splice sleeve connections for 
reinforced precast concrete column-to-cap beam joints in accelerated bridge construction," PCI Journal, vol. 60, pp. 6080-6103, 2015.

[15] S. Kevin, P. Rajesh, and J. Dhakal, "Seismic performance of damage-protected beam-column joints," ACI Structural Journal, vol. 105, no. 2, pp. 105205-105214, 2008.

[16] Y. Ryo and S. David, "Seismic performance of precast unbonded prestressed concrete columns," ACI Structural Journal, vol. 106, no. 6, pp. 106821-106830, 2009.

[17] Q. Yu, Grouted Sleeve Lapping Connector, CN 204238449 U, 2015.

[18] Q. Yu and Z. Xu, "Experimental study of grouted sleeve lapping connector under tensile load," Građevinar, vol. 69, pp. 69453-69465, 2017.

[19] Q. Yu, X. Gong, Y. Fang, Z. Xu, and X. Lu, "Grouted sleeve lapping connector and component performance tests," Revista Tecnica de la Facultad de Ingenieria Universidad del Zulia, vol. 39, pp. 39136-39145, 2016.

[20] Q. Yu, K. Xu, Z. Xu, Y. Fang, and X. Lu, "Seismic behavior of precast shear walls with vertical reinforcements overlap grouted in constraint sleeve," Revista Tecnica de la Facultad de Ingenieria Universidad del Zulia, vol. 39, pp. 39207-39217, 2016.

[21] C. D. Department, Code for Design of concrete Structures, China Architecture \& Building Press, Beijing, China, 2014.

[22] C. D. Department, Specification of Test Methods for Earthquake Resistant Building, China Architecture \& Building Press, Beijing, China, 2015.

[23] A. Committee, Building Code Requirements for Structural Concrete and Commentary, American Concrete Institute Committee, Farmington Hills, Michigan, 1999.

[24] X. L. Gu, Basic Principle of concrete Structure, Tongji University Press, Shanghai, China, 2004.

[25] C. D. Department, Code for Seismic Design of Buildings, China Architecture \& Building Press, Beijing, China, 2014. 